\title{
Apartamento mínimo contemporâneo: desenvolvimento do conceito de uso como chave para obtenção de sua qualidade
}

\author{
Minimum contemporary apartment: development of the \\ concept of use as key for obtaining its quality
}

\section{Rafaela Nunes Mendonça Simone Barbosa Villa}

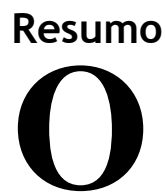

fenômeno da minimização de apartamentos é uma realidade vista em um número expressivo de imóveis comercializados no Brasil, apresentando soluções de projeto insatisfatórias e pouco adequadas às questões referentes aos modos de morar da atualidade. Por isso, é fundamental analisar esses espaços, buscando formas de atenuar tais problemas, por meio do entendimento dos usos. Este artigo é parte integrante da pesquisa de mestrado "Apartamentos mínimos contemporâneos: análises e reflexões para obtenção de sua qualidade" desenvolvida no Programa de Pós-Graduação em Arquitetura e Urbanismo - Faculdade de Arquitetura Urbanismo e Design (FAUeD) da Universidade Federal de Uberlândia (UFU), financiada pela Fundação de Amparo à Pesquisa do Estado de Minas Gerais (Fapemig). Tem por objetivo principal analisar as inadequações geradas pela minimização dos apartamentos e seus efeitos sobre os modos de morar, e sugerir que a relação mais intensa entre o design e a arquitetura possa nortear a melhoria da qualidade funcional desses espaços. Para tanto, este artigo mantém seu foco nos aspectos de desempenho do conceito de uso, que vão desde os elementos arquitetônicos que formam o espaço até as atividades realizadas no ambiente doméstico e suas sobreposições. Foram obtidas análises que permitiram visualizar o desempenho e o papel do conceito de uso, percebendo que a habitação e seu conjunto de mobiliário e equipamentos fazem parte de um processo variável e dinâmico.

Palavras-chaves: Edifício de apartamento. Qualidade funcional. Comportamento e modo de vida. Processo de projeto. Design.

\begin{abstract}
The phenomenon of minimizing apartments is a view reality in a significant number of properties sold in Brazil, with unsatisfactory and inappropriate design solutions for contemporary ways of life. Therefore, it is crucial to analyze these spaces, seeking ways to mitigate such problems through understanding the uses. This article is part of the Master thesis "Minimum contemporary apartments: development of the concept of use as key for obtaining its quality" developed in the Graduate Program in Architecture and Urbanism - School of Architecture Planning and Design (FAUeD) of the Federal University of Uberlândia (UFU), funded by Fapemig. Its main objective is to analyze the inadequacies generated by the minimization of apartments, its effects on the ways of living, indicating parameters to guide the improvement of the functional quality of these spaces, through closer interaction between design and architecture. Focuses on the performance aspects of the concept of use, ranging from the architectural elements that make up the space to the activities performed in the household and their overlaps. The analysis allowed us to visualize the performance and role of the concept of use, obtaining as results the recommendations intended to produce the minimum apartment, realizing that a dwelling and its furniture and equipment are part of a variable and dynamic process.
\end{abstract}

Simone Barbosa Uberlândia - MG - Brasil

Recebido em 26/09/15 Aceito em 27/05/16

Keywords: Building. Functional and environmental quality. Behaviour and way of life. Design process. Design.

MENDONÇA, R. N.; VILLA, S. B. Apartamento mínimo contemporâneo: desenvolvimento do conceito de uso como 


\section{Introdução}

A minimização das habitações é vista como solução aparentemente econômica pelo mercado imobiliário. Contudo, é notória a rigidez, estanqueidade e padronização com que são tratados e caracterizados os projetos de habitações do tipo apartamentos. O fato é que, considerando as complexas necessidades dos usuários sujeitas à dinâmica da sociedade e da cultura, a arquitetura e o design exercem a "[...] função mediadora entre produção e uso [...]" (BONSIEPE, 1983, p. 94; FOLZ, 2008, p. 58), a partir do momento em que a tomada de consciência sobre a relevância das características culturais, de hábitos e costumes dos usuários, dos aspectos físicos do local onde se inserem as habitações, é possível produzir visando a qualidade da moradia, especialmente em relação à usabilidade e apropriação do espaço por parte de seus usuários.

Segundo Bonsiepe (1983), o espaço habitável, "habitat", e os produtos, "artefatos materiais", são análogos na medida em que se afirmam como resultado da intervenção humana no intuito de uma maior e melhor interação, ou seja, a moradia está simbioticamente relacionada ao mobiliário e aos equipamentos, uma vez que são produzidos para serem experimentados pelo usuário de forma direta na sua vida cotidiana (BONSIEPE, 1983; LÖBACH, 2001). Também se pode afirmar que, especialmente no que diz respeito ao mobiliário, uma de suas capacidades é a de requalificar o espaço da habitação, assim como contribuir para sua organização e funcionamento (LÖBACH, 2001; DEVIDES, 2006).

Quando se abre discussão sobre a habitação contemporânea, a questão da adequação espacial aos usuários ressoa no âmbito da arquitetura e do design, intrigando os que se dedicam ao desenvolvimento de moradias de qualidade. Nesse sentido torna-se relevante analisar as inadequações geradas pela minimização dos apartamentos e seus efeitos sobre os modos de morar, sugerindo a relação mais intensa entre o design e a arquitetura e norteando a melhoria da qualidade funcional desses espaços. Para isso a pesquisa ${ }^{1}$, na qual este artigo se insere, objetiva a análise e compreensão da relação entre as demandas da sociedade e os conceitos capazes de qualificar tais apartamentos, identificando inadequações e recomendações para sua melhoria. Os principais conceitos trabalhados na pesquisa foram: uso, flexibilidade, apropriação, adaptação, privacidade e ergonomia. Para tanto, este artigo mantém seu recorte nos aspectos de

${ }^{1}$ Pesquisa de mestrado, desenvolvida nos anos 2013-2015 pelo Programa de Pós-Graduação em Arquitetura e Urbanismo, FAUED-UFU. desempenho do conceito de uso, que vão desde os elementos arquitetônicos que formam o espaço até as atividades realizadas no ambiente doméstico e suas sobreposições.

Os objetos de estudo desta pesquisa foram os apartamentos contemporâneos frequentemente produzidos pelo mercado imobiliário em cidades de médio porte, tendo a cidade de Uberlândia, MG, como exemplar, destinados à classe média da sociedade. Tal recorte social se deve à notoriedade recebida nos últimos anos por seu volume e demanda de mercado, haja vista seu evidente crescimento socioeconômico. Para o desenvolvimento de parte da pesquisa foram elencados dois estudos de caso lançados pelo mercado imobiliário local (Uberlândia), nos últimos cinco anos (2010-2015), com tipologias de dois e três dormitórios. Também são objetos de estudo os equipamentos e mobiliário essenciais à dinâmica doméstica, disponíveis em lojas de varejo, localizadas na cidade, porém de abrangência nacional. Vale ressaltar que esse mestrado se insere em uma pesquisa maior, financiada pelo CNPq, intitulada "Habitar vertical: avaliação da qualidade espacial e ambiental de edifícios de apartamentos"2.

Os procedimentos metodológicos da pesquisa foram:

(a) pesquisa bibliográfica acerca dos modelos de habitação do tipo apartamento;

(b) pesquisa bibliográfica sobre as demandas da sociedade contemporânea;

(c) pesquisa bibliográfica sobre conceitos qualificadores do espaço habitacional: noções de uso, flexibilidade, apropriação, adaptação, privacidade e ergonomia;

(d) seleção e análise de fichas de dados sobre os empreendimentos da cidade de Uberlândia ${ }^{3}$, bem como dos equipamentos e mobiliário doméstico,

\footnotetext{
${ }^{2}$ Pesquisa financiada pelo CNPq (demanda universal), desenvolvida de 2012 a 2014, no grupo de pesquisa "[Mora] Pesqyusa em Habitação" do Núcleo de Pesquisa em Projeto de Arquitetura da FAUED-UFU. O objetivo foi realizar um diagnóstico da qualidade espacial e ambiental em edifícios de apartamentos destinados à classe média e lançados pelo mercado imobiliário em cidades de médio porte brasileiras (Ribeirão Preto, SP, e Uberlândia, MG). Tal análise foi fundamentada, principalmente, por meio da aplicação de avaliação pós-ocupação em relação aos aspectos funcionais e ambientais dos edifícios. Esta pesquisa contou com um banco de dados que computa aproximadamente 500 exemplos cadastrados de edifícios de apartamentos produzidos a partir do ano de 2000 nas cidades médias brasileiras, dentre as quais se enquadra a cidade de Uberlândia.

${ }^{3}$ Para isso utilizou-se o banco de dados da pesquisa "Habitar vertical", indicada anteriormente.
} 
para verificação e listagem de exemplos e padrões dimensionais;

(e) pesquisa e análises acerca de ações positivas de design e arquitetura, para os interiores residenciais e mobiliários, mais atentos às demandas dos usuários contemporâneos;

(f) escolha de dois estudos de caso localizados na cidade de Uberlândia, a partir de critérios prédeterminados;

(g) análises pós-ocupacionais nos estudos de caso a fim de identificar maneiras de morar;

(h) análises gráficas nos estudos de caso compatibilizando os conceitos estudados e os modos de morar levantados em etapas anteriores; e

(i) elaboração de recomendações orientadoras para projetos de apartamentos.

Como o presente artigo trata especificamente dos aspectos de desempenho do conceito de uso, metodologicamente se apoia em pesquisas bibliográficas e documentais, além de consultas e análises de dados, dos documentos fornecidos pela pesquisa "Habitar vertical". Também conta com o método observacional (avaliação pós-ocupação), que possibilitou o contato com moradores dos edifícios analisados, em que se pôde observar os fatos de maneira natural e verificar os usos da habitação de acordo com seus modos de vida, hábitos e costumes, bem como os perfis familiares. Por fim, foram desenvolvidas análises gráficas, enfocando os aspectos de desempenho do conceito de uso dos espaços analisados. A partir dessas análises conclui-se que seja possível promover uma organização do arranjo da habitação de forma otimizada e coerente com as exigências dos moradores e seus modos de morar. As análises possibilitaram a verificação dos problemas da habitação em responder ao conceito e permitiram a visualização do desempenho e papel do conceito de uso, considerado um dos principais qualificadores dessa habitação.

\section{Fenômeno da minimização dos apartamentos contemporâneos}

Com base em estudos já consolidados sobre a moradia do tipo apartamento, é possível introduzir essa discussão com um breve histórico sobre a evolução e os fatores sociais que encaminharam para o atual modelo de habitação (RYBCZYNSKI, 1996; TRAMONTANO, 1997; VILLA, 2002; BRANDÃO, 2003; FOLZ, 2005). Esses estudos evidenciam que, em meados do século XIX, adotou-se um programa para espaços habitacionais baseados nas necessidades identificadas na família burguesa europeia da Belle Époque (VILLA,
2002). Esse período caracterizava-se, segundo Rybczynski (1996), pela conquista da domesticidade. Quando instituída a família nuclear - composta pelo pai, mãe e filhos - desenvolvemse as noções de intimidade e privacidade, caracterizando a habitação como lar, um ambiente doméstico para o desenvolvimento familiar. Baseada nessa estrutura familiar, foram estipuladas as principais características e a organização a que a moradia e seu conjunto de móveis deveriam corresponder, estabelecendo-se, então, o modelo tripartido da habitação.

Posteriormente, num panorama de modificações sociais, econômicas, culturais e técnicas advindas da Revolução Industrial, nasce a arquitetura moderna (BENEVOLO, 1998). O desenvolvimento do cenário habitacional coletivo é impulsionado por fatores como déficit habitacional, superpopulação, condições precárias de higiene e edificações inseguras. Essas situações estimularam a racionalização na reconstrução das cidades e a implementação de projetos que utilizavam e buscavam novos materiais e métodos facilitadores para uma produção estandardizada da habitação (FINKELSTEIN, 2009; FOLZ, 2005).

Nessa perspectiva, durante o Congresso Internacional de Arquitetura Moderna (CIAM), em 1929, ocorreu o debate sobre a Existenzminimum (habitação para o mínimo nível de vida), a fim de discutir as bases para definição do padrão mínimo para a habitação (BENEVOLO, 1998; FOLZ, 2005). Buscando ir além de uma simples relação de metragem quadrada por pessoa, considerou-se que a concepção de uma habitação mínima envolveria resoluções de amplas necessidades biológicas e psicológicas no sistema estático da construção em si (FINKELSTEIN, 2009; FOLZ, 2005; KENCHIAN, 2005). Pode-se afirmar que desde então habitações mínimas e padrões de qualidade mínimos para se morar têm sido amplamente discutidos no âmbito da arquitetura e urbanismo.

Por conseguinte, transformações despontam principalmente no campo tecnológico. Modificações referentes aos modos de morar seguiram fazendo com que arranha-céus, eletrodomésticos e uma variada gama de produtos se tornassem objetos de desejo. Nessa euforia do consumismo a habitação é "[...] elevada à categoria de bem de consumo [...]" (TRAMONTANO, 1997, p. 2). Em relação às alterações sociais, o individualismo e o dinamismo asseguraram a fragmentação da família nuclear. Além disso, reivindicações femininas pelos seus direitos e a postura a qual a mulher assume foram fundamentais para a nova organização familiar (TRAMONTANO, 1997; VILLA, 2002). São 
percebidos então, em meados do século XXI, novos agrupamentos familiares e aumento no número de pessoas que vivem sozinhas. Despontados outros fatores como o encurtamento dos processos de informação e da necessidade de deslocamento, o fenômeno da globalização se intensifica, assim como a informatização e a digitalidade, com o estabelecimento de relações inovadoras entre as pessoas e a tecnologia, e o remodelamento do quadro social a um ambiente hiperconectado (TRAMONTANO, 1997; REQUENA, 2007).

Compreende-se então que a atual realidade apresenta uma sociedade imersa nessas e em outras tantas modificações constantes, que se refletem tanto nos hábitos, costumes, e modos de pensar como nos modos de morar. A questão retumbante frente ao exposto é: por que ainda conservar um traçado de habitação tripartida, caracterizada pela monofuncionalidade e estanqueidade, visto que tal modelo, aplicado em áreas com dimensões exíguas, mostra-se ineficiente e atende minimamente os modos de morar contemporâneos? A análise apresentada na Figura 1 evidencia essa conservação do modelo tripartido de habitação.

Observa-se que os apartamentos são a realidade de moradia de muitas pessoas, não somente em cidades grandes, mas, sobretudo, em cidades de médio porte. Essas pessoas, distribuídas em grupos domésticos variados, optam por esse modelo de moradia por vários motivos, como por exemplo: segurança, praticidade, localização próxima a centros de interesse cotidiano (PINHO, 2005) e, principalmente, economia; afinal, esses imóveis possuem condições de compra mais acessíveis atualmente. Contudo, a reprodução ativa do modelo de habitação tripartida se agrava pela rigidez e estanqueidade que esses espaços apresentam, frente a áreas diminutas, para atender as necessidades de moradores dos mais diversos (BRANDÃO, 2002, 2003; KENCHIAN, 2005 , VILLA, 2008; FOLZ, 2008).

\section{Figura 1 - Análise das características do modelo tripartido de planta aplicado em apartamentos contemporâneos, reduzidos}

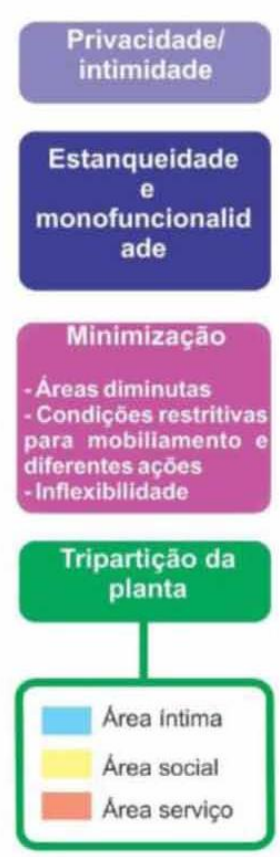

Imagem:

Edificio Residencial Bilbao, 2011 - Uberiandia Fonte: Fichas da pesquisa 'Habitar vertical'

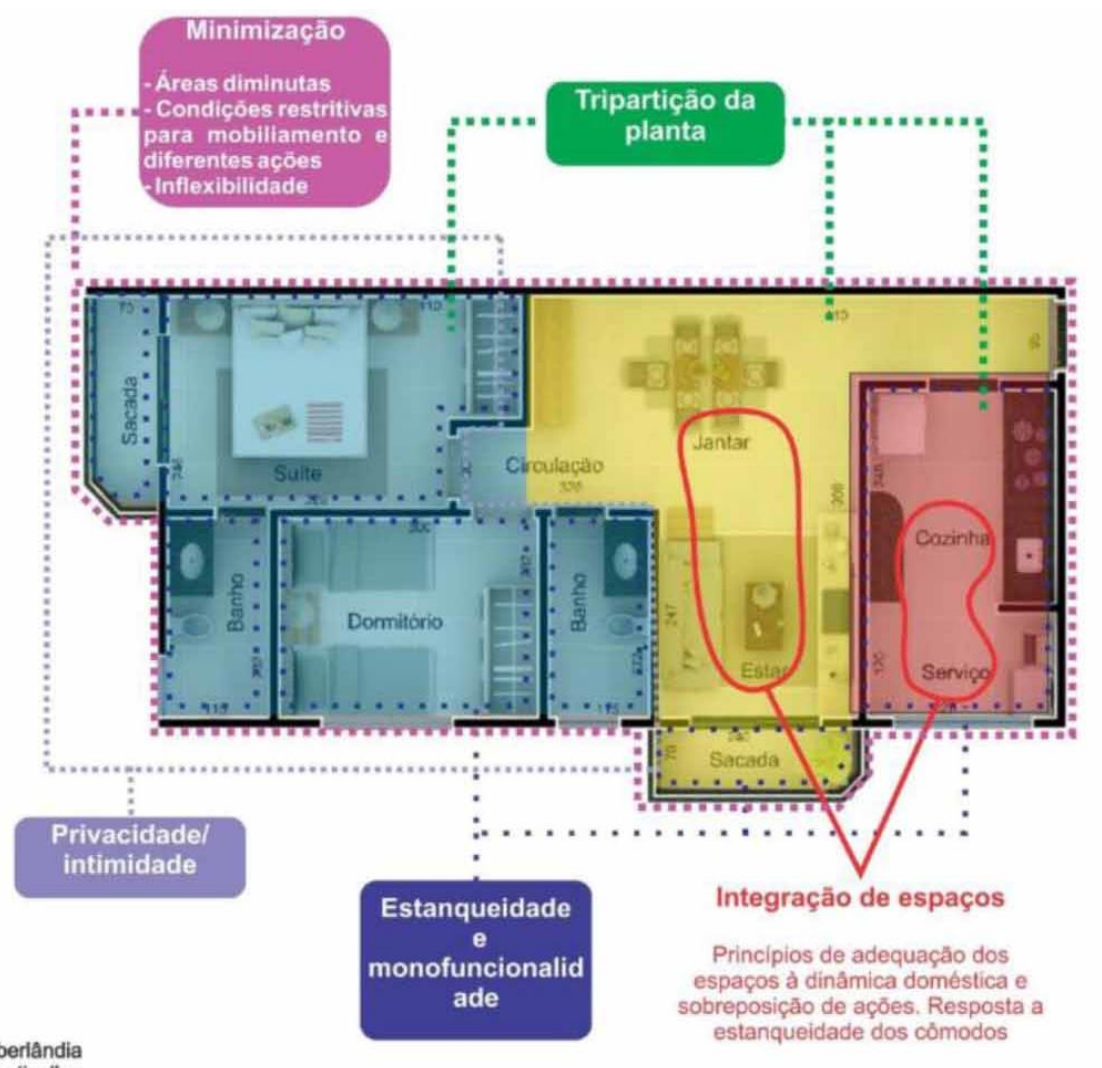

254 Mendonça, R. N.; Villa, S. B. 
Percebe-se que fatores como a superestimação dos imóveis e o fenômeno da minimização dos apartamentos já é fato firmado em cidades brasileiras onde o aumento do custo dos terrenos é um dos motivos que levam as incorporadoras a reformatarem seus produtos. As estratégias adotadas de maximização das taxas de lucro do capital de incorporação consistem na minimização do capital investido e/ou na diminuição do tempo de retorno desse capital (CARVALHO, 2008; VILLA, 2008; FOLZ, 2002; TRAMONTANO, 2006). Para isso investe-se em publicidade e todo o processo para concepção e execução de um projeto arquitetônico adequado se torna irrelevante. O papel do arquiteto está fadado a meras "contribuições estéticas para o produto", quando os agentes imobiliários respondem às necessidades dos usuários de maneira maquiada, percebendo que a publicidade opera muito mais incisivamente, no sentido de transformar desejos em necessidades (VILLA, 2008).

Sendo assim, a minimização aqui discutida não está fadada apenas à limitação de área útil da habitação, mas em verificar as condições restritivas que proporciona ao morador, no que diz respeito ao uso e à apropriação. Folz (2008) afirma que os padrões adotados atualmente para a produção de habitações mínimas ainda aceitam normas ultrapassadas e áreas inferiores ao mínimo determinado por vários estudos (BOUERI, 1989), e não consideram as especificidades regionais, $\mathrm{O}$ que acaba dificultando o pareamento com peculiaridades culturais, familiares e subjetivas dos usuários (BOUERI, 2008; FOLZ, 2008; KENCHIAN, 2005).

Para refletir sobre essas questões de inadequação vinculada à minimização, o Quadro 1 expõe algumas definiçõos de dimensões de áreas, de pesquisas realizadas por Boueri (1989, 2008), atentando-se à habitação brasileira, e por Pedro (2002, 2011, 2014), com estudos voltados ao contexto da habitação portuguesa. As pesquisas desenvolvidas por esses autores analisam, de modo geral, as condições da habitação com relação ao uso, às ações domésticas cotidianas e à adequação física e ergonômica, detendo-se no mobiliário e nos equipamentos que compõem o espaço doméstico. Dessa maneira, discorrem sobre como deveriam ser colocados os padrões dimensionais mínimos, de modo que não prejudique, mas acrescente qualidade de vida aos seus usuários.

Contudo, o presente estudo utiliza como principal referência as análises desenvolvidas por Pedro (2002, 2011, 2014) devido a sua ampla abordagem quanto à qualidade espacial e funcional de projetos habitacionais e explanações minuciosas quanto aos seus principais condicionantes, que vão do programa da habitação, dos espaços e compartimentos até o desempenho do mobiliário na moradia. Considerou-se também o fato de que estudos realizados em conjunto pelos dois pesquisadores (BOUERI; PEDRO; SCOARIS, 2012) verificaram semelhanças metodológicas; no entanto, mostram que as diferenças se estabelecem devido ao contexto social e econômico, que se reflete em diferentes níveis de exigências adotados como parâmetros em ambos os países.

Para a formulação do quadro comparativo foram inseridos os valores apresentados por Boueri e Pedro conforme suas respectivas considerações sobre áreas mínimas, recomendáveis e ideais, em paralelo com as áreas adotadas em um apartamento contemporâneo, lançado em 2010 na cidade de Uberlândia, como exemplo de apartamento frequentemente ofertado no mercado imobiliário, não só regional, mas nacional.

\section{Quadro 1 - Comparativo entre as áreas indicadas por Pedro e Boueri, em relação às áreas ofertadas,} sob o exemplo de um empreendimento local

\begin{tabular}{|c|c|c|c|c|c|c|c|}
\hline \multirow{2}{*}{ Ambiente } & \multicolumn{2}{|c|}{$\begin{array}{l}\text { Area minima } \\
\qquad \mathrm{m}^{2}\end{array}$} & \multicolumn{2}{|c|}{$\begin{array}{l}\text { Area recomendável } \\
\qquad \mathrm{m}^{2}\end{array}$} & \multicolumn{2}{|c|}{$\begin{array}{c}\text { Area ideal } \\
\mathrm{m}^{2}\end{array}$} & \multirow{2}{*}{$\begin{array}{c}\text { Area } \\
\text { ofertada: } \\
m^{2}\end{array}$} \\
\hline & Boueri & Pedro & Boueri & Pedro & Boueri & Pedro & \\
\hline DORMITÓRIO CASAL. & 12 a 9 & 10,5 & 12 a 15 & 11,5 & 18 a 15 & 12,0 & 8,80 \\
\hline DORM. SOLTEIRO DUPLO & 10 a 8 & 9,0 & 12 a 10 & 10,0 & 15 a 12 & 11,0 & 8,16 \\
\hline DORM. SOLTEIRO SIMPLES & 9 a 8 & - & 10 a 9 & - & 12 a 10 & - & 7,87 \\
\hline $\begin{array}{l}\text { SALAS } \\
\text { (JANTAR E ESTAR) }\end{array}$ & 12 a 9 & 14,0 & 15 a 12 & 18,0 & 18 a 15 & 21,0 & 13,95 \\
\hline BANHO & 5,0 a 4,5 & 2,5 & 5,5 a 5,0 & 2,5 & 6 a 5,5 & 3,0 & 2,88 \\
\hline COZINHA & 8 a 6 & 5,0 & 10 a 8 & 6,0 & 12 a 10 & 6.5 & 5,35 \\
\hline SERVIÇO & 8 a 6 & 2,0 & 10 a 8 & 3,0 & 12 a 10 & 3,5 & 2,39 \\
\hline
\end{tabular}

Fonte: Boueri (2014), Pedro (2002) e fichas avaliativas dos empreendimentos fornecidas pelo grupo de Pesquisa Habitar Vertical (2013).

Nota: *área da unidade de apartamento, Uberlândia, com referência ao ano de 2010. 
Embora no quadro haja indicações numericamente maiores em alguns cômodos do apartamento contemporâneo, com relação aos valores indicados como mínimo pelos pesquisadores, não se pode afirmar de imediato que esses espaços se adaptam às variadas exigências do usuário. Como explicado por Pedro (2014), para que a habitação estabeleça o nível mínimo ${ }^{4}$ de qualidade, é preciso que ela satisfaça as necessidades elementares do cotidiano doméstico de cada morador, sem os prejudicar ou restringir significativamente seus modos de vida.
É nesse sentido que são considerados como principais conceitos qualificadores da habitação o uso, a flexibilidade, a adequação, a ergonomia, a privacidade e a apropriação. Afinal, considera-se como aspectos capazes de assegurar condições satisfatórias à habitação, segundo as percepções do usuário, frente aos diversos fatores que o formam, como cultura, hábitos e características da sociedade na qual se insere, e devem ser tomados como partidos desde o projeto. O Quadro 2 expõe esses conceitos e os aspectos aos quais se relacionam.

\section{Quadro 2 - Conceitos qualificadores}

\begin{tabular}{|c|c|c|}
\hline \multicolumn{3}{|c|}{ CONCEITOS QUALIFICADORES } \\
\hline & CONCEITO & ASPECTOS AOS QUAIS SE RELACIONAM \\
\hline USO & 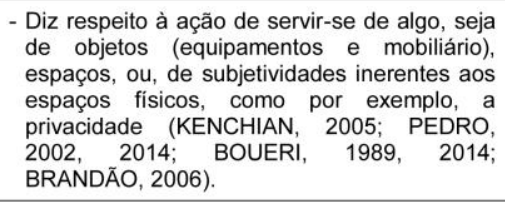 & $\begin{array}{l}\text { - Ações e atividades domésticas previstas (convivência, } \\
\text { manutenção do corpo, da mente e da casa, trabalho/ } \\
\text { aumento de renda, estocagem/armazenagem) } \\
\text { - Condicionantes: usuários, tempo, elementos de } \\
\text { setorização, móveis e equipamentos }\end{array}$ \\
\hline FLEXIBILIDADE & $\begin{array}{l}\text { - Capacidade de adaptação de algo a uma } \\
\text { nova exigência. Assume um papel } \\
\text { fundamental na viabilidade social, econômica } \\
\text { e ambiental de um produto (ABREU, 2005; } \\
\text { ABREU e HEITOR, 2007; SCHNEIDER e } \\
\text { TILL, 2005a, 2005b). }\end{array}$ & $\begin{array}{l}\text { - Processo construtivo e tecnologia, usabilidade e } \\
\text { funcionalidade, adaptabilidade }\end{array}$ \\
\hline ADEQUAÇĀO & $\begin{array}{l}\text { - Trata da capacidade de tornar a habitação } \\
\text { mais ajustada em relação aos usuários e } \\
\text { seus hábitos na medida em que permite } \\
\text { acomodação dos usos essenciais da } \\
\text { habitação, sem restringir as necessidades } \\
\text { dos usuários relativas ao conforto e } \\
\text { agradabilidade, espaciosidade e e } \\
\text { funcionalidade, assim como de segurança e } \\
\text { mobilidade (PEDRO, 2014; BOUERI, 2008). }\end{array}$ & $\begin{array}{l}\text { - Aspectos fisicos: conforto térmico, acústico, visual e } \\
\text { conforto do corpo } \\
\text { - Aspectos físico-funcionais: circulação, articulação e } \\
\text { mobilidade, adaptabilidade, acessibilidade e } \\
\text { segurança }\end{array}$ \\
\hline APROPRIAÇÄO & $\begin{array}{l}\text { - Relaciona-se à capacidade de atender a } \\
\text { subjetividade dos usuários, colaborando para } \\
\text { que o habitante possa adaptar o espaço ou } \\
\text { objeto a si, imprimindo neles suas } \\
\text { necessidades de individualidade funcional, } \\
\text { fisicas e principalmente sua memória } \\
\text { (afetividade) } \\
\text { HERTZBERGER, 1996). }\end{array}$ & $\begin{array}{l}\text { - Flexibilidade, adequação, } \\
\text { funcionalidade, personalização. }\end{array}$ \\
\hline PRIVACIDADE & $\begin{array}{l}\text { - Capacidade de controlar aquilo que se deseja } \\
\text { expor ou informar sobre si, sobre a } \\
\text { particularidade pessoal de um individuo ou de } \\
\text { um grupo de pessoas que estabelecem } \\
\text { alguma relação (PEDRO, 2002) }\end{array}$ & $\begin{array}{l}\text { - Aspectos territoriais: espaços privados, semiprivados, } \\
\text { semipúblicos } \\
\text { - Aspectos de compatibilidade: compatibilidade de } \\
\text { atividades simultâneas, sucessivas, alternativas e } \\
\text { incompativeis }\end{array}$ \\
\hline ERGONOMIA & $\begin{array}{l}\text { - Ciência que aborda a interação saudável } \\
\text { entre homem e tarefa, envolve questões } \\
\text { fisicas, biológicas, psicológicas e de } \\
\text { tecnologia (PANERO e ZELNIK, 2002; } \\
\text { BOUERI, 2008; KENCHIAN, 2005) }\end{array}$ & $\begin{array}{l}\text { - Habitante/ usuário: aspectos físicos e psicossomáticos } \\
\text { - Ações: segundo os usuários } \\
\text { - Mobiliário e equipamentos: segundo as atividades } \\
\text { domésticas } \\
\text { - Espaço: movimentos de uso (corpo em relação ao } \\
\text { espaço e/ou objeto), circulação, estado de } \\
\text { permanência (posições do usuário: de pé, sentado ou } \\
\text { deitado) }\end{array}$ \\
\hline
\end{tabular}

\footnotetext{
${ }^{4}$ Pedro $(2002,2014)$ realiza estudos sobre o programa da habitação, desde o espaço construído - edifício, seus cômodos, vizinhança e a dimensão do mobiliário e equipamentos, definindo três níveis de qualidade para o programa habitacional: mínimo, recomendável e ótimo. Esses níveis representam diferentes escalas referentes à satisfação das necessidades dos usuários, em que o nível mínimo é aquele que satisfaz as necessidades básicas do cotidiano doméstico dos usuários evitando-se convergir para restrições e prejuízos aos modos de vida pessoais.
} 
Inerente aos conceitos apresentados, é importante abordar a questão da adaptabilidade, pois desponta como uma característica de arquitetura e design, que alia estratégias espaciais, de serviços e também estruturais, que permitem ao produto físico construído um nível de maleabilidade, o que possibilita responder às mudanças de parâmetros de usabilidade ao longo do tempo (SCHMIDT et al. 2010; BARROS; PINA, 2012; BRANDÃO, 2002; SCHNEIDER; TILL, 2005a, 2005b). A adaptabilidade pode ser entendida como mudança estratégica, que reflete em produtos considerados não como um projeto finalizado, mas como objeto imperfeito, em constante evolução funcional, tecnológica e estética para responder à metamorfose da sociedade (SCHMIDT et al., 2010). Para tanto, os responsáveis pelos projetos de habitações necessitam de uma metodologia que viabilize a participação dos moradores, oferecendo a eles amplas condições de uso e, principalmente, orientações e capacidade de interferir de maneira saudável em sua moradia (BARROS; PINA, 2012).

Tais conceitos, portanto, agem diante do fenômeno da minimização dos apartamentos, predispondo uma habitação sustentável em face da longevidade do tempo, a partir do momento em que se inclina a facilitar diferentes usos de acordo com os vários modos de morar (PEDRO, 2002; KENCHIAN, 2011). Acredita-se que assim é possível tratar a habitação mínima em toda sua complexidade econômica, social, construtiva e funcional, proporcionando benefícios econômicos tanto para o mercado e agentes imobiliários quanto para seus usuários; afinal, não se trata apenas de uma tendência, mas de uma exigência da sociedade contemporânea e seus novos modos de morar.

\section{Resultados}

Nos itens a seguir, são apresentados os resultados, que consistem em reflexões e análises realizadas de acordo com os seguintes passos:

(a) seleção e redesenho dos estudos de caso;

(b) confrontação das medidas constatadas com as medidas indicadas segundo o nível mínimo determinado por Pedro (2002);

(c) verificação de condições restritivas de cunho arquitetônico conforme os determinantes construtivos, físicos e funcionais;

(d) compatibilização do leiaute apresentado pelas imobiliárias com móveis e equipamentos levantados, segundo as dimensões físicas e de uso desses objetos, pautando-se pelo nível mínimo proposto por Pedro (2011); (e) verificação dos usos e modos de morar a partir do reconhecimento dos usuários dos apartamentos estudados; $\mathrm{e}$

(f) compatibilização dos usos e modos de morar, constatados através da pesquisa com o usuário, com o leiaute gerado a partir da inserção dos móveis e equipamentos levantados, considerando todas as etapas anteriormente citadas.

Os estudos de caso foram eleitos segundo os seguintes critérios:

(a) apartamentos ofertados pelo mercado imobiliário da cidade de Uberlândia (2010-2015);

(b) variação tipológica: dois e três dormitórios, com ou sem suíte;

(c) área útil média: dois dormitórios $\left(66,95 \mathrm{~m}^{2}\right) \mathrm{e}$ três dormitórios $\left(108,87 \mathrm{~m}^{2}\right)$;

(d) destinados às classes médias ${ }^{5}$;

(e) valor médio do metro quadrado $\left(\mathrm{m}^{2}\right)$ até $\mathrm{R} \$ 2$ $\mathrm{mil} / \mathrm{m}^{2}$ (referência 2014);

(f) produzidos e lançados por incorporadoras e/ou construtoras de abrangência regional e/ou local, e outra de alcance nacional; e

(g) menor área útil de acordo com a variação tipológica ${ }^{6}$.

O Quadro 3 apresenta os apartamentos selecionados como estudo de caso, destacando especialmente um comparativo entre as áreas úteis divulgadas e as constatadas pelo redesenho da planta.

\section{Que "casa" é essa? Análises dos agentes condicionantes da usabilidade}

Os Quadros 4 e 5 introduzem as análises com reflexões sobre os apartamentos e suas áreas. A verificação foi possível a partir do redesenho das plantas, com base nas medidas fornecidas pelo material publicitário. Os aspectos analisados foram as áreas de cada cômodo em correspondência com as áreas cujas dimensões são determinadas como mínimas por Pedro (2002). Lembrando que as dimensões mínimas propostas por Pedro (2002, 2011, 2014) são assim denominadas pois correspondem ao nível mínimo de qualidade por ele determinado.

\footnotetext{
${ }^{5} \mathrm{Para}$ definição desse critério foram considerados na escolha dos apartamentos: (i) área útil da unidade, padrão do empreendimento, localização do empreendimento, valor médio do metro quadrado.

${ }^{6}$ Com base no banco de dados da pesquisa "Habitar vertical", foram escolhidos os apartamentos de menor área útil que se enquadravam em todos os critérios.
} 
Quadro 3 - Ficha de apresentação dos apartamentos - dados gerais

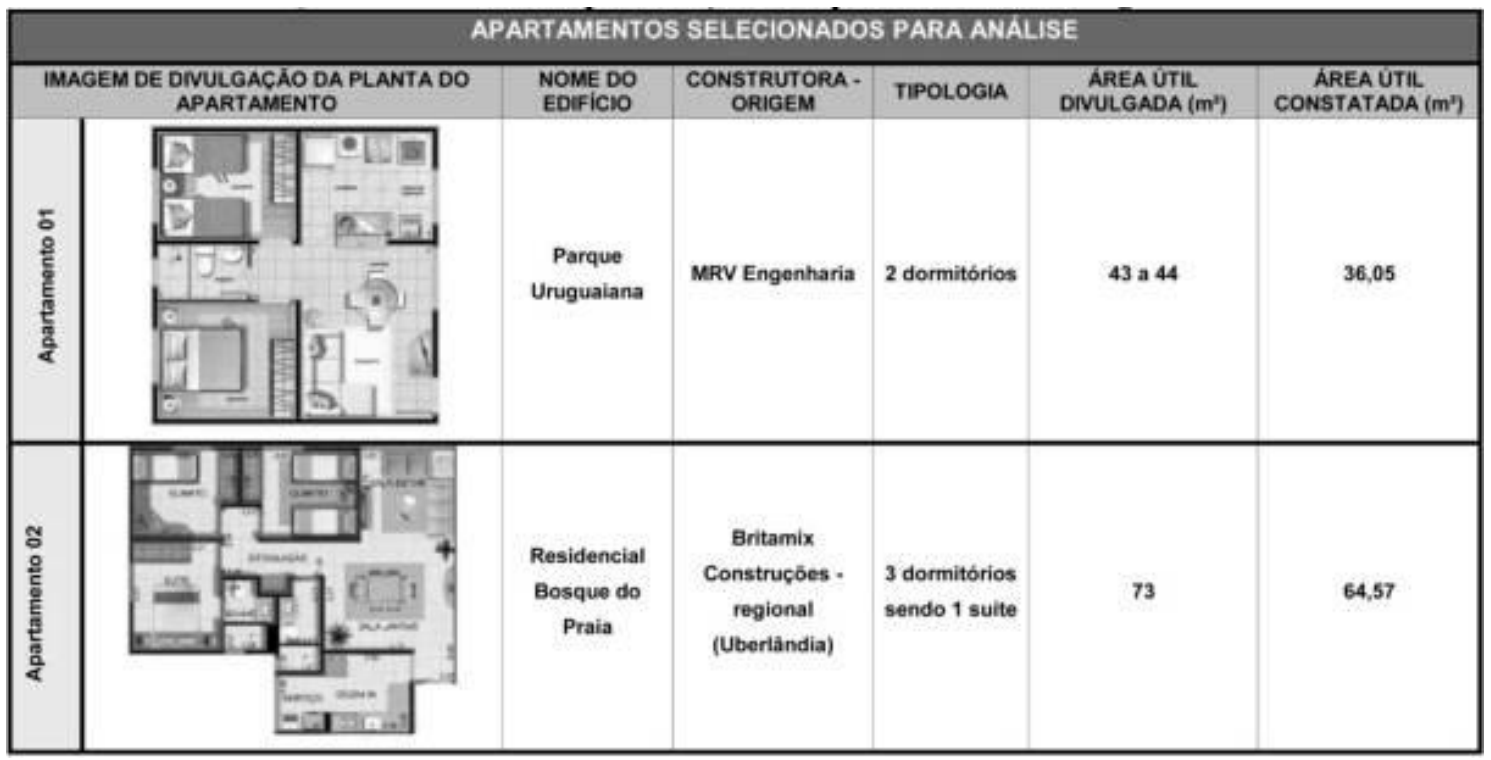

Quadro 4 - Ficha de apresentação dos apartamentos - dados específicos

\begin{tabular}{|c|c|c|c|c|}
\hline \multicolumn{5}{|c|}{ APARTAMENTO 01 - 2 DORMITORIOS } \\
\hline \multicolumn{2}{|c|}{ PLANTA } & CÔMODOS & $\begin{array}{l}\text { AREAS OBTIDAS } \\
\text { POR REDESENHO } \\
\text { (M') }\end{array}$ & $\begin{array}{l}\text { AREA MINIMA } \\
\text { SEGUNDO } \\
\text { PEDRO }\end{array}$ \\
\hline \multirow{3}{*}{ Dormitorio 2} & \multirow{3}{*}{$\begin{array}{l}\text { Cazinha Serviço } \\
\mathrm{C} \\
\end{array}$} & Dormitório casal & 7,20 & 10,5 \\
\hline & & $\begin{array}{l}\text { Dormitório solteiro } \\
\text { (duplo ou simples) }\end{array}$ & 7,20 & 9,0 \\
\hline & & Salas & 10,86 & 14,0 \\
\hline Bantheiro & \multirow{4}{*}{ Salas } & Banho & 2,40 & 2,5 \\
\hline \multirow{3}{*}{ Dormitóxio 1} & & Cozinha & 5,34 & 5,0 \\
\hline & & Serviço & 1,85 & 2,0 \\
\hline & & TOTAL. & 36,05 & - \\
\hline
\end{tabular}

Quadro 5 - Ficha de apresentação dos apartamentos - dados específicos

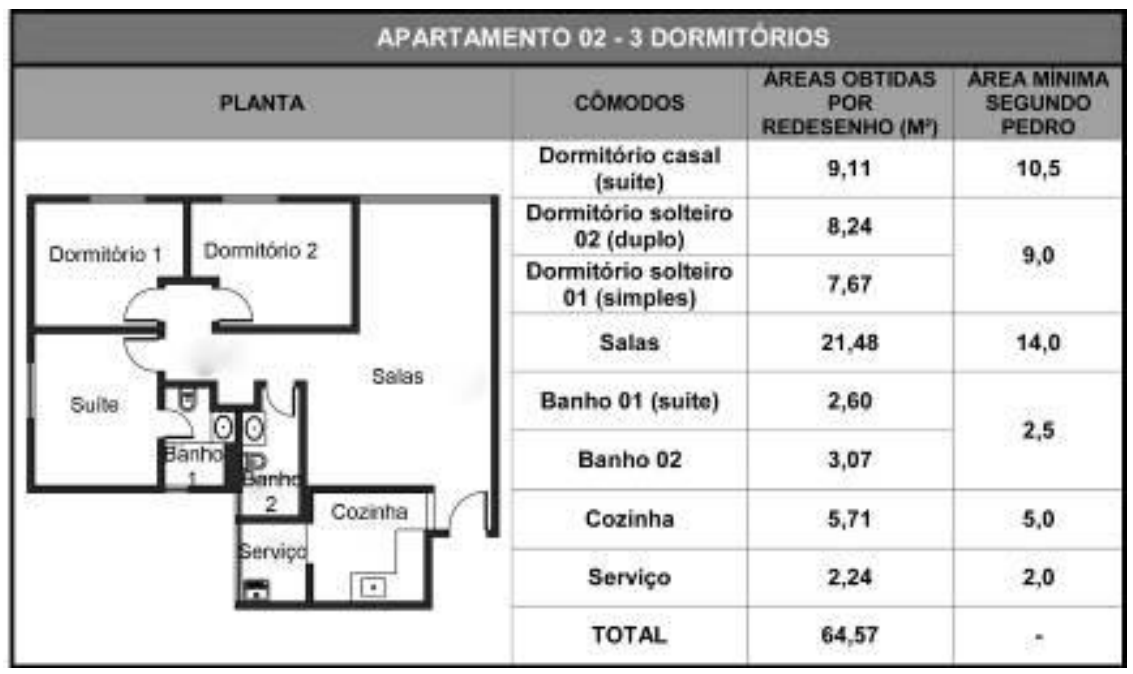


É importante esclarecer que as indicações sobre a área útil total da habitação, segundo o nível mínimo proposto por Pedro (2002, 2011, 2014), não foram inseridas nos quadros 4 e 5 , pois o autor afirma que cada caso exige uma especificidade para determinação de sua área mínima, devendo ser considerados aspectos diversos, como, por exemplo, número de moradores e elementos construtivos arquitetônicos, como a posição das fachadas. Portanto, para afirmar qual a área total recomendada pelo autor, nas situações acima, seriam necessárias outras investigações específicas, obedecendo a sua metodologia, o que não compete a este estudo.

É possível notar, a partir do redesenho e do quadro elaborado, que existem cômodos com valores bastante inferiores aos valores mínimos de referência, como no caso dos dormitórios e salas do Apartamento 1. No entanto, mesmo que em alguns casos existam áreas pouco maiores que as consideradas mínimas por Pedro (2002), não se pode afirmar que estas amenizam a inadequação com relação à espaciosidade e limitação de áreas úteis. Afinal, há de se considerar a organização desses espaços e como eles se dispõem no apartamento como um todo, assim como a hierarquização e também alguns elementos determinantes da programação do leiaute e da dinâmica interna do apartamento, para que então se afirme ao menos o nível mínimo de qualidade.

Nesse sentido, as Figuras 2 e 3 apresentam análises feitas a partir da verificação das características de cunho arquitetônico, de acordo com as informações verificadas in loco e por pesquisa nos sites das construtoras. A fundamentação se dá pela pesquisa bibliográfica realizada sobre aspectos que interferem na dinâmica do espaço, bem como para a qualidade do ambiente construído (PEDRO, 2002; KENCHIAN, 2005, 2011; BRANDÃO, 2003; VILLA; ORNSTEIN, 2013; ABREU, 2005).

Figura 2 - Apontamentos de aspectos contribuintes nos efeitos negativos da minimização - Apartamento 1

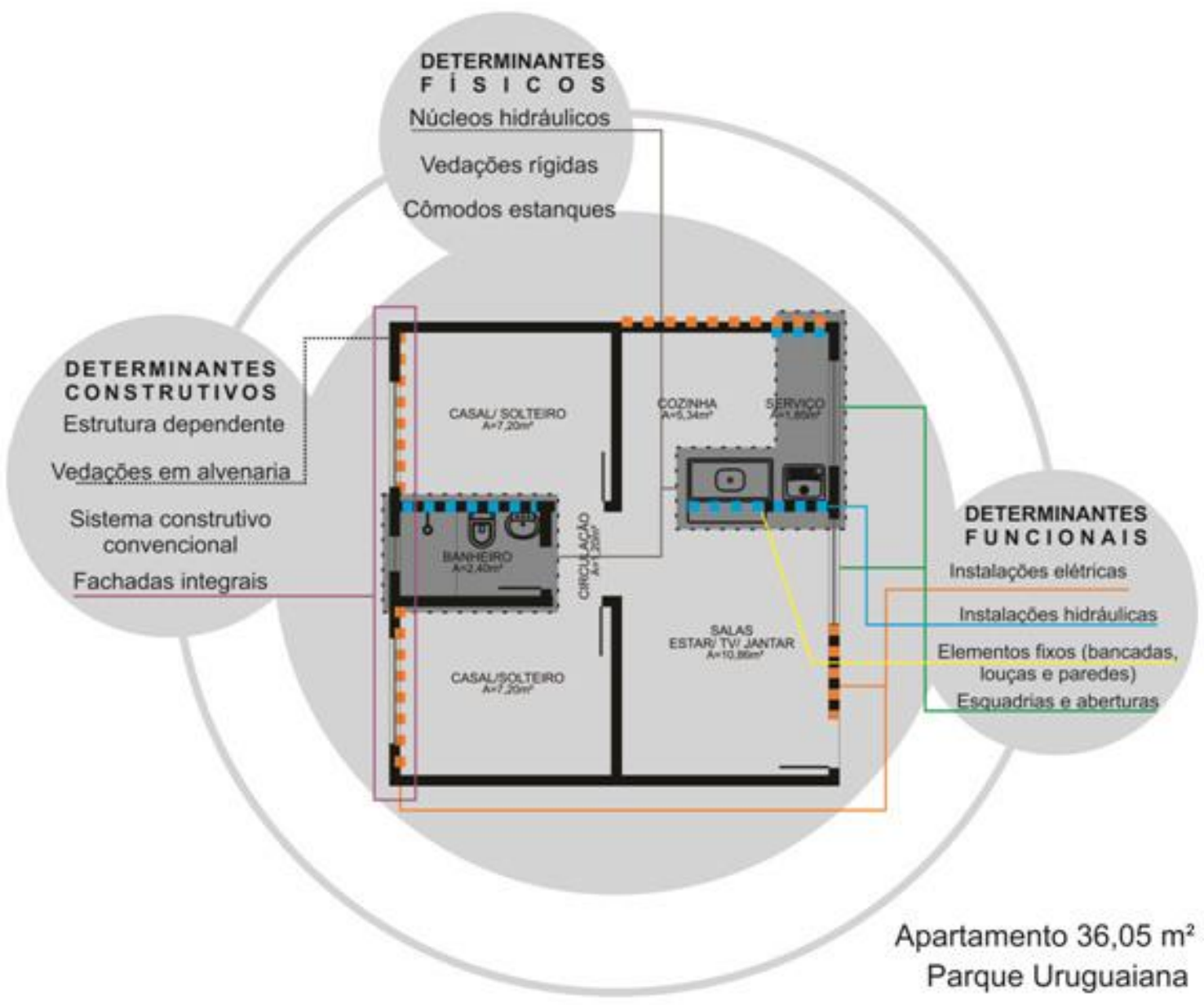


Figura 3 - Apontamentos de aspectos contribuintes nos efeitos negativos da minimização - Apartamento 2

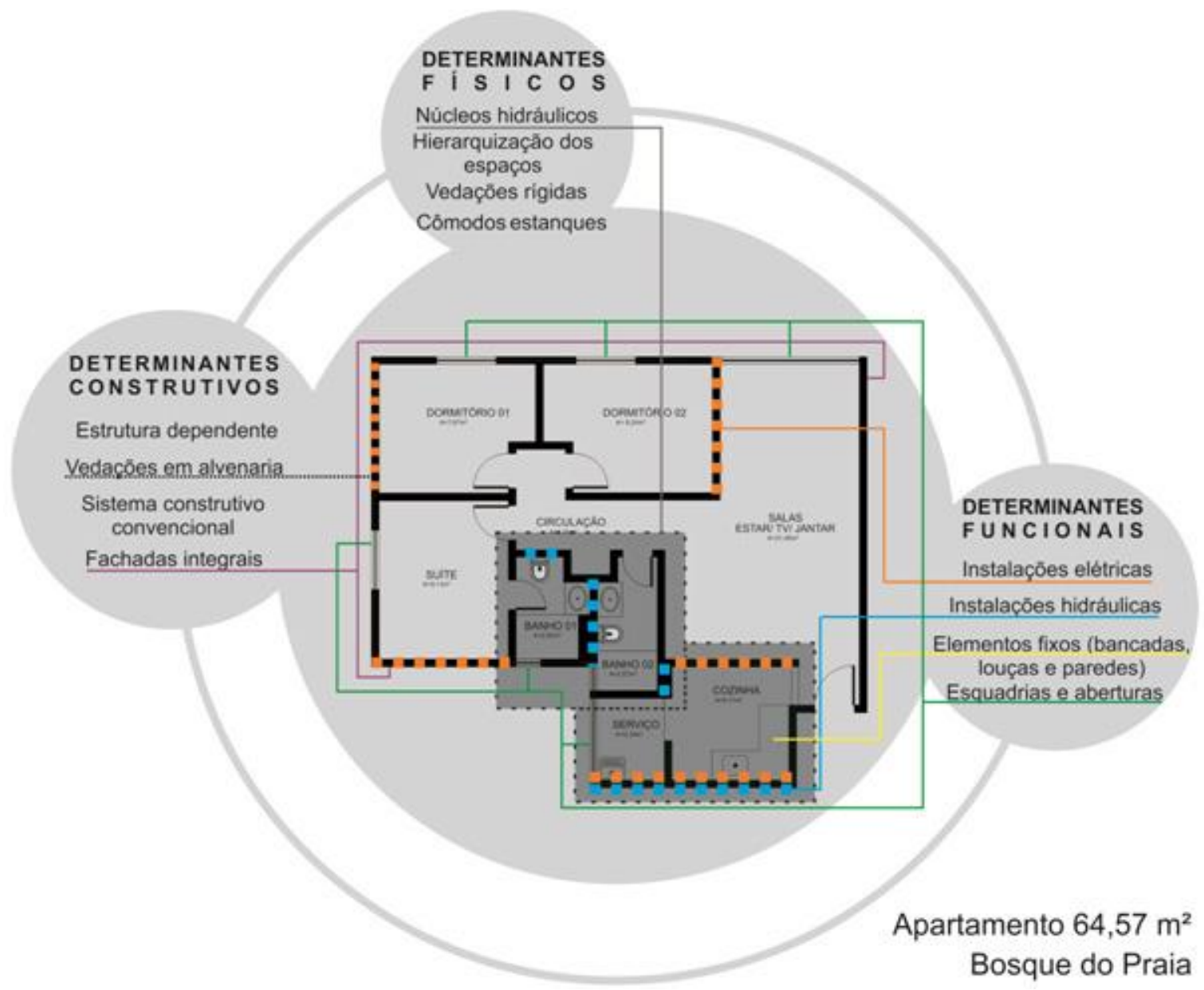

As análises consideram fatores que se caracterizam como determinantes, e refletem não somente na organização e formação do espaço, condicionando os seus arranjos espaciais, mas principalmente em como se dará a usabilidade do espaço. Cada um dos determinantes possui aspectos que os caracterizam, formando conjuntos que se relacionam.

Com isso, nos dois apartamentos observa-se que os determinantes construtivos abrangem o tipo de estrutura e a vedação, assim como a forma da fachada. O sistema construtivo adotado possui características convencionais, ou seja, não apresenta tecnologias industriais ou outro sistema de construção (GREVEN; BALDAUF, 2007), que, aliado ao sistema de alvenarias estruturais, impede qualquer alteração e/ou processos de adaptabilidade construtiva (SCHMIDT et al., 2010; SCHNEIDER; TILL, 2005b). Mesmo que sejam modificações de pequeno porte, como, por exemplo, o deslocamento de pontos elétricos, podem oferecer riscos à integridade da estrutura do edifício. Com isso, percebe-se a necessidade de considerar, primeiramente, os aspectos construtivos do edifício como condicionantes do espaço residencial e das prováveis configurações de arranjos, pois a partir dele também se estabelecem os determinantes físicos e funcionais da habitação (ABREU, 2005; SCHNEIDER; TILL, 2005a, 2005b).

Sobre determinantes físicos, entende-se como aqueles capazes de definir a distribuição do espaço interno da habitação (ABREU, 2005). Nesse sentido, procurou-se destacar a disposição dos núcleos que oferecem serviços essenciais, como a água e o esgoto (núcleos hidráulicos), cuja localização é fixa, e por isso deveriam ser mais bem avaliados desde a fase de projeto, para que seu posicionamento seja estratégico e não um empecilho para a configuração geral dos espaços da habitação. Tratando de apartamentos mínimos, seria oportuna a concentração, formando um único núcleo hidráulico, abastecido por uma linha de instalações hidráulicas, a fim de viabilizar a economia construtiva e a otimização da dinâmica da habitação em relação aos seus usos, capacitando 
assim a habitação para a flexibilidade (ABREU, 2005; SCHNEIDER; TILL, 2005a, 2005b).

Outros aspectos que fazem parte desse conjunto de determinantes físicos são as próprias vedações, que por sua vez compõe os cômodos. A partir do momento em que essas vedações se tornam elementos rígidos ${ }^{7}$, configuram-se espaços estanques, dificultosos quanto à adequação e flexibilização, principalmente quando apresentam áreas enxutas. A alteração de qualquer elemento que esteja inserido nessas vedações, ou sua simples retirada, pode gerar desperdícios, além de custos, resíduos construtivos e reparos (ABREU, 2005; PEDRO, 2002; KENCHIAN, 2011).

No tocante aos determinantes funcionais, foram considerados os seguintes aspectos condicionantes: instalações hidráulicas e elétricas, vãos de esquadrias e aberturas, assim como alguns elementos fixos como bancadas e louças, frequentemente presentes em espaços como banheiros e cozinha. Entende-se por determinantes funcionais aquilo que auxilia no desenvolvimento de atividades inerentes à habitação, contribuindo de certo modo para a determinação de espaços onde essas atividades poderão ser desenvolvidas de acordo com a dinâmica exigida pelos modos de vida de seus usuários, sem restrições ou prejuízos (ABREU, 2005; KENCHIAN, 2011; PEDRO, 2002, 2014; SCHNEIDER; TILL, 2005b). No entanto, percebe-se que na maioria das propostas de habitações, principalmente apartamentos, esses determinantes são apresentados de maneira rígida e tendem a oferecer ambientes monofuncionais, que inviabilizam a sobreposição de atividades, resultando nas mais variadas dificuldades de adequação.

Sinalizados alguns pontos exemplificadores dessas dificuldades oriundas do mau entendimento e aplicação acerca dos determinantes funcionais, pode-se perceber que existem aglomerações rígidas de pontos elétricos e hidráulicos cuja ausência ou quantidade insuficiente desses pontos em outras localizações do espaço influencia na configuração do arranjo de equipamentos e mobiliário no espaço, inviabilizando assim a mobilidade e rearranjo do espaço. Para racionalizar e buscar solução para esses problemas, existem propostas que vão ao encontro das estratégias de flexibilidade (ABREU, 2005), como, por exemplo, a adoção de pisos elevados e/ou forros rebaixados que facilitem o acesso a essas instalações e, consequentemente, possibilitem a relocação de pontos (hidráulicos, elétricos) sem grandes ônus. Também, os elementos fixos como bancadas podem proceder de maneira dificultosa quando não instalados de maneira estratégica. Uma solução, além da locação estratégica e de preferência nuclearizada com outros elementos que exigem certa fixação, seria a utilização de elementos dotados de certa mobilidade.

Quanto aos vãos de esquadrias e aberturas, a partir do momento em que são planejados em projeto e efetuados na construção do edifício não há como modificá-los, especialmente quando se trata de componentes da fachada do edifício (ABREU, 2005; PEDRO, 2002, 2014). Como não compete a essa discussão tratar do aspecto estrutural e arquitetônico do edifício em geral, apenas se faz importante a provocação no sentido de que sejam propostas novas formas e aplicações desses elementos, em que as esquadrias apresentem soluções alternativas e inteligentes para compor as fachadas; afinal, é por meio desses elementos que se estabelece a comunicação com o espaço exterior.

Todos esses determinantes demonstrados nas análises agem diretamente sobre a usabilidade da habitação e o arranjo do ambiente, constituído por um conjunto de equipamentos e mobiliário, assim como por espaços de ações ${ }^{8}$. Sendo assim, quando adotados de maneira rígida, acabam restringindo as variações do leiaute e, consequentemente, podem ocasionar inadequações e incompatibilidades na relação do espaço com o mobiliário e equipamento, e deles com os usuários e seus modos de vida.

\section{Será que cabe? Análise segundo as dimensões físicas e de uso}

A análise apresentada a seguir (Figura 4) foi desenvolvida para evidenciar, nos apartamentos estudados, quais os pontos críticos com relação às dimensões físicas e de uso do conjunto de mobiliário e equipamentos, de acordo com o leiaute proposto pelas construtoras. Para tanto, conta-se com dados dos levantamentos desses objetos, que foram selecionados a partir dos seguintes critérios:
${ }^{7}$ Por rígido, ou rigidez, entende-se aquilo que restringe de alguma maneira a qualidade e o bom desempenho dos artefatos (espaços construídos, habitação, mobiliário, equipamentos) produzidos para interface com o usuário. Geralmente pode ser caracterizado como um elemento que é fixo, que restringe a mobilidade, e de certo modo seja instransponível ou difícil de ser alterado.
${ }^{8}$ Considera-se como "espaço de ações" espaços para movimentação do corpo humano ao realizar atividades utilizando o mobiliário/equipamento, seja para circulação ou uso. 
(a) presença no leiaute divulgado pelas construtoras;

(b) essenciais à dinâmica doméstica, com bases no conhecimento das atividades relacionadas ao conceito de uso;

(c) disponíveis em lojas de varejo, localizadas na cidade, porém de abrangência nacional, cujos departamentos ofereçam os produtos de interesse;

(d) dimensões físicas (largura, profundidade e altura) iguais ou mais próximas das dimensões recomendadas como mínimas por Pedro (2011).

Selecionados os objetos, foram verificadas as dimensões mínimas de uso, também recomendadas por Pedro (2011), que, confrontadas com o espaço e de acordo com o leiaute proposto, apresentaram pontos de sobreposição prejudicial das dimensões de uso. Para a evidenciação desses pontos, foram considerados também aspectos físico-funcionais (circulação, articulação, mobilidade, acessibilidade e segurança).

Portanto, a análise é baseada no fato de que o mobiliário e o equipamento doméstico são fundamentais no desenvolvimento das atividades domésticas, e é importante que sejam ponderados seus padrões dimensionais físicos e de uso, entendendo como se refletem no arranjo e na dinâmica dos usos dos moradores (PEDRO, 2011; BOUERI, 2014). Afinal, conforme Pedro (2011), o mobiliário e equipamento, somados aos usos e às atividades domésticas, são fundamentais para determinantes de áreas e dimensões de cada espaço da habitação.

Considerando a possibilidade de que o morador, ao adquirir uma habitação, por vezes utiliza a planta disponibilizada pela construtora, como exemplo de configuração do espaço, assim como para ensaiar a disposição do mobiliário e do equipamento que possui, e o que pretende vir a adquirir, a informação disponibilizada nas plantas dos folhetos publicitários deveria se comprometer com as dimensões usuais dos elementos de mobiliário disponíveis no mercado (PEDRO, 2011). Contudo, observa-se que nem sempre essas representações estão ajustadas à realidade. Entretanto, há de se considerar também que o leiaute apresentado segue algumas condições instauradas em projeto, que é o caso dos determinantes apresentados no item anterior que, como visto, acabam por condicionar a organização do arranjo no espaço.

Figura 4 - Zonas críticas de sobreposição das dimensões físicas e de uso do mobiliário

Apartamento 01 - Layout

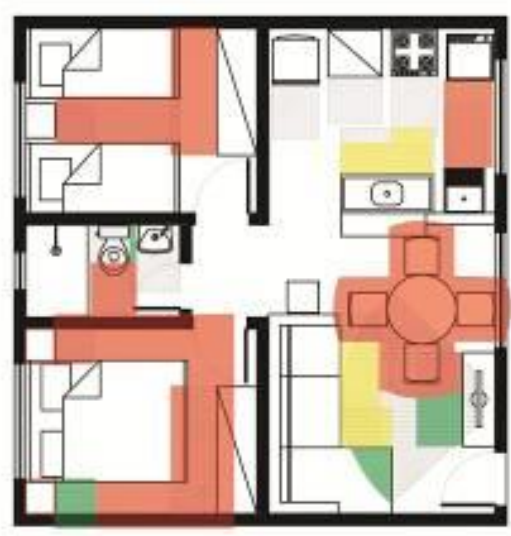

Pontos criticos de dimensões físicas

Mơvel não pode ser inserido no espaço

Pontos criticos de dimensōes de uso

Sobreposiçăo prejudicial

Sobreposiçāo pouco prejudicial

Sobreposiç̧̄o positiva
Apartamento 01 - Layout

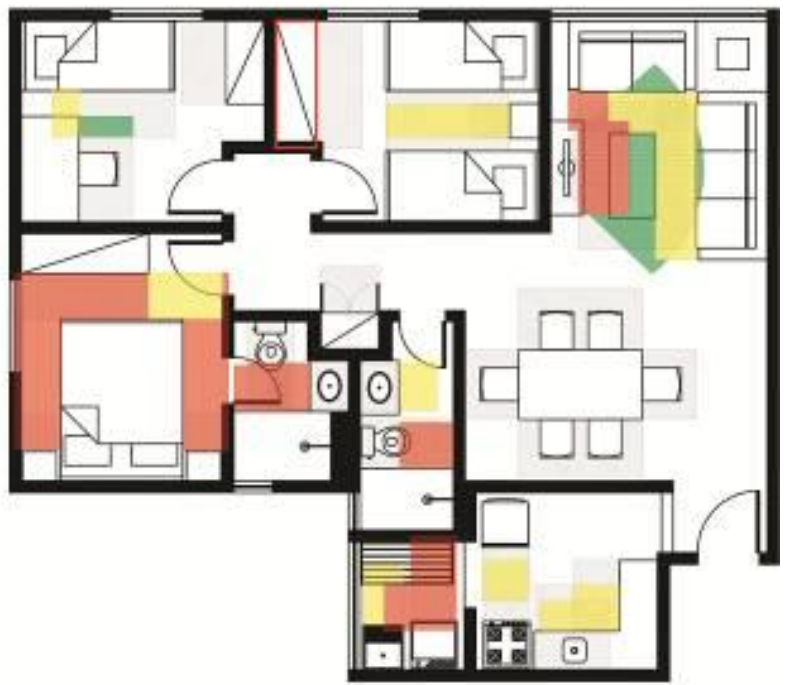

262 Mendonça, R. N.; Villa, S. B. 
$\mathrm{Na}$ Figura 4, portanto, percebem-se indicações das incompatibilidades entre as medidas físicas do espaço e mobiliário, assim como os pontos críticos relacionados à dimensão de uso, utilizando-se de uma escala, que qualifica a sobreposição das dimensões de uso em três níveis:

(a) sobreposição prejudicial, onde há conflitos entre dimensões de usos de diversos móveis e equipamentos, ou inviabilização da dimensão mínima de uso em decorrência da exiguidade e rigidez dos espaços;

(b) sobreposição pouco prejudicial, indicando pontos em que pode haver conflitos entre as dimensões de uso de móveis e equipamentos; e

(c) sobreposição positiva, apontando sobreposições que não interferem ou prejudicam, de alguma maneira, a utilização do móvel e/ou equipamento.

Pode-se dizer que o reflexo do ainda reproduzido modelo de habitação burguês que insiste na presença de diversos compartimentos para cada um dos usos é insatisfatório frente à rigidez espacial e agravado por áreas tão diminutas que interferem não somente na dinâmica dos usos domésticos, mas na adequação e até mesmo nas possibilidades de escolha do conjunto de mobiliário e equipamento. Nota-se então que existem dificuldades em equipar e mobiliar os apartamentos, especialmente seguindo como referência leiaute proposto no material de divulgação. Além disso, o leiaute proposto mostrase defasado para atender, de maneira qualificada, os modos de vida dos moradores, principalmente em se tratando do atendimento ao perfil familiar nuclear (subentendido pela configuração do leiaute), não se atentando às possíveis modificações que esses usuários sofrerão no passar dos anos.

Um dos efeitos dessas restrições e dificuldades de adequação dimensional é o abastecimento do mercado de "móveis planejados", em que, no intuito de qualificar e adequar o lugar onde moram, alguns usuários optam por investir em móveis feitos sob medida, de acordo com necessidades específicas e por vezes até momentânea, o que sugere riscos de adaptação às mudanças que podem surgir. Na maioria dos casos, esses móveis, produzidos a partir de dimensões e necessidades peculiares, são dotados da mesma rigidez dos espaços. Ou seja, podem apresentar ausência ou dificuldades de fornecer dois aspectos fundamentais ao mobiliário, para que ele cumpra com o papel de requalificador dos espaços: a modularidade, que auxilia, por exemplo, em possíveis adaptações físicas e formais, e a flexibilidade, característica capaz de dar ao móvel diferentes possibilidades de usos e funções. Contudo, essa discussão implica outra abordagem, além de estudos mais aprofundados.

\section{Como mora? Análise de usos}

As análises de usos foram desenvolvidas considerando os grupos de usos, formados pelas atividades previstas como "essenciais" à dinâmica doméstica, indicando, assim, pontos críticos que se referem às restrições sobre os usuários dos apartamentos estudados. Para tanto, procedeu-se da seguinte forma:

(a) entendimento dos usos de acordo com a discriminação de atividades consideradas essenciais à dinâmica doméstica;

(b) verificação dos usos e modos de morar a partir de análises pós-ocupacionais;

(c) mapeamento dos usos na planta, de acordo com as etapas anteriores;

(d) compatibilização do conceito, das dimensões físicas e de usos dos espaços e seu conjunto de mobiliário e equipamento, com os resultados sobre os modos de morar, identificando zonas críticas com relação à dificuldade em corresponder satisfatoriamente os usos mapeados. Sendo assim, a análise é fundamentada nos estudos bibliográficos que se referem aos usos, bem como nos resultados obtidos das verificações e análises pós-ocupacionais.

Foram consideradas as seguintes atividades:

(a) recebimento de convidados, entretenimento de crianças/jovens, entretenimento de adultos/casais e entretenimento familiar;

(b) higiene pessoal, refeições, sono/descanso pessoal, estudos, trabalhos, relaxamento;

(c) cuidados com alimentos, cuidados com limpeza, cuidados com roupas;

(d) trabalho fora do expediente e/ou trabalho para aumento de renda; e

(e) arrumação e conservação de utilidades pessoais, domésticas e alimentícias (PEDRO, 2014; VILLA, 2008).

Sobre a verificação dos modos de vida, foi realizada uma pesquisa empírica complementada com a aplicação de questionários, segundo os métodos de avaliação pós-ocupação (APO), contando com uma amostragem de 30\% das habitações em relação ao total de apartamentos ocupados nos edifícios (descritos na página 200) durante o segundo semestre de 2014. Tal procedimento contribuiu de modo a formular previsões, avaliando as possibilidades que um 
determinado acontecimento pode gerar (BERNARD, 2005). Por isso a importância dessas atividades de contato com os usuários e constatações frente às análises de usos, pois a partir das hipóteses lançadas pôde-se desenvolver análises gráficas, que partem em um primeiro momento da visão do avaliador sobre as informações fornecidas pelas situações e pelos moradores, contribuindo para a programação e orientações de projetos, relacionados à qualificação da habitação.

Sendo assim, este artigo apresenta as partes do método e de seus resultados que se mostraram mais relevantes para a exploração do conceito de uso, pois são fundamentais para a compreensão das análises gráficas que seguirão. $\mathrm{O}$ Quadro 6 apresenta o método que foi apoiado nos procedimentos de APO, seu procedimento, objetivos e atributos avaliados.
Os resultados foram compilados em gráficos (Figura 5), e permitiram identificar várias características dos usuários em relação aos seus modos de vida, cultura e também entender como eles percebem e utilizam o espaço, assim como alguns aspectos sobre a relação de identificação com a moradia e seu conjunto de equipamentos e mobiliário. Entretanto, para este artigo foram selecionados alguns mais relevantes para o entendimento das análises aqui presentes.

A primeira característica, mais geral e por sua vez condicionante, trata da identificação do perfil familiar, em que ainda há predominância da família nuclear. Contudo, esse perfil tem "perdido as forças", dividindo sua posição com outros arranjos familiares, especialmente os arranjos de casais DINC ${ }^{9}$, famílias monoparentais e pessoas que moram sozinhas.

\section{Quadro 6 - Procedimentos metodológicos elencados para a APO, objetivos e atributos avaliados}

\begin{tabular}{|c|c|}
\hline OBJETIVOS DA TÉCNICA & ATRIBUTOS GERAIS AVALIADOS \\
\hline \multicolumn{2}{|c|}{ 1. Levantamento Geral de Dados - Pesquisador (avaliador) } \\
\hline \multicolumn{2}{|c|}{$\begin{array}{l}\text { Possibilitar aos pesquisadores (avaliadores) o acesso às informações e ao edifício a ser avaliado; } \\
\text { levantamento dos dados iniciais; } \\
\text { contatos para a viabilidade da APO no edifício; }\end{array}$} \\
\hline \multicolumn{2}{|c|}{ 2. Pesquisa de Perfis Familiares - Funcionários e Morador (usuário) } \\
\hline $\begin{array}{l}\text { Possibilitar aos pesquisadores avaliadores a } \\
\text { identificação do perfil familiar dos moradores - quais } \\
\text { são as predominâncias de grupos familiares no edificio }\end{array}$ & $\begin{array}{l}\text { Foram divididos em } 8 \text { grupos: família nuclear, família } \\
\text { nuclear expandida, família monoparental, coabitação, } \\
\text { pessoas sós, casal de idosos e DINKS, família } \\
\text { monoparental expandida. }\end{array}$ \\
\hline \multicolumn{2}{|c|}{ 3. Questionário com Análise de Usos - Morador (usuário) } \\
\hline $\begin{array}{l}\text { Nível de satisfação dos usuários: espaços privados; } \\
\text { Níveis de apropriação e privacidade dos usuários; } \\
\text { Quais os motivadores para aquisição do apartamento no } \\
\text { edifício estudado; } \\
\text { Quais as aspirações (desejos e sonhos) em relação à } \\
\text { moradia; } \\
\text { Identificação das atividades realizadas nos respectivos } \\
\text { cômodos; } \\
\text { Presença de sobreposição de atividades; } \\
\text { Adequação dos mobiliários; } \\
\text { Aspectos positivos e negativos dos espaços. }\end{array}$ & $\begin{array}{l}\text { Características do entrevistado; } \\
\text { Nível de satisfação dos usuários (espaços privados e } \\
\text { espaços semiprivados); } \\
\text { Impressão geral do usuário em relação à unidade de } \\
\text { apartamento; } \\
\text { Identidade e grau de adaptabilidade / apropriação - } \\
\text { adequação dos espaços da unidade; } \\
\text { Análise da tarefa - lista de atividades ou ações por } \\
\text { cômodo; } \\
\text { Levantamento da unidade - organização do layout, } \\
\text { registro fotográfico. }\end{array}$ \\
\hline \multicolumn{2}{|c|}{ 4. Relatórios descritivos e comentados - Pesquisador (avaliador) } \\
\hline $\begin{array}{l}\text { Avaliar o quanto o projeto arquitetônico proposto } \\
\text { atende aos modos de vida dos usuários; } \\
\text { Avaliar quais as possíveis alterações para melhoria da } \\
\text { qualidade dos espaços, a partir de uma proposta de } \\
\text { design. }\end{array}$ & $\begin{array}{l}\text { Resultados dos questionários; } \\
\text { Mapeamento comportamental e estudos de ações; } \\
\text { Propostas de adequação do projeto ao modo de vida } \\
\text { dos usuários; }\end{array}$ \\
\hline
\end{tabular}

\footnotetext{
${ }^{9}$ Double income and no children - Dupla renda e nenhum filho.
} 
Figura 5 - Perfis familiares identificados na amostra

\section{Apartamento 01}

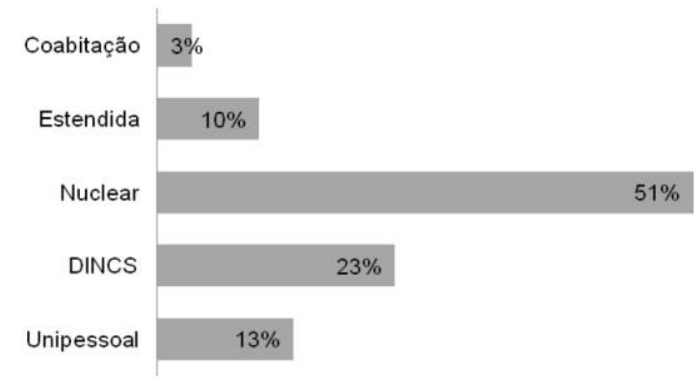

Outros dados relevantes são sobre a percepção dos moradores frente às questões de dimensionamento da habitação e da dificuldade para desenvolver atividades do cotidiano doméstico. De acordo com a pesquisa, os moradores relataram que as dimensões de seus cômodos realmente eram diminutas, porém alegavam não haver dificuldades em realizar a maioria das atividades (Figura 6). No edifício do Apartamento 2 as dificuldades mencionadas se concentravam em atividades que exigiam maior movimentação do corpo, como, por exemplo, entretenimento, ou o fato de receber visitas, assim como atividades de manutenção da casa, como, por exemplo, lavar roupas (Figura 7). Já com os moradores do Apartamento 1 as queixas maiores se concentravam nas atividades de manutenção, principalmente a lavagem de roupas, assim como dificuldades com a estocagem, o ato de cozinhar e o recebimento de pessoas. É interessante que, durante a aplicação dos questionários, muitos moradores exclamavam que algumas atividades como estudar, trabalhar, receber pessoas e em alguns casos até mesmo lavar as roupas não eram atividades realizadas por eles. Dos motivos apontados, um diz respeito à ausência de condições ou espaço suficiente para que ocorressem, tendo então que se habituar a tais restrições.

Nessa perspectiva, nota-se que o conceito de uso se afirma como o pilar para o desempenho de quaisquer outros conceitos que agem no sentido de dar qualidade à habitação. Afinal, o usuário e seu comportamento no espaço são o cerne da questão sobre a qualificação da habitação. Assim, as análises gráficas e descritivas dos dois apartamentos, apresentadas a seguir, procuram evidenciar os usos notados em cada apartamento e os pontos de maior conflito e inadequação, fundamentados por todo o processo de pesquisa adotado, ou seja, associando os estudos bibliográficos realizados acerca do conceito, com os resultados das pesquisas empíricas e de APO. Portanto, as análises associam os usos prováveis

\section{Apartamento 02}

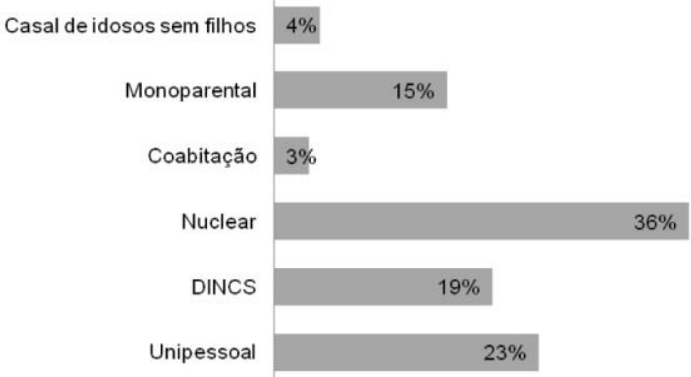

para o local e os usos mínimos esperados, constatando também se o conjunto de equipamentos e mobiliário é compatível com esses usos mínimos, bem como indicam as zonas críticas de sobreposição das dimensões físicas e de uso desses componentes no espaço.

As análises (Figuras 8 e 9) apresentam indicações de grupos de usos, que envolvem atividades e diferentes ações. Percebe-se primeiramente que há uma variedade grande de usos previstos para cada cômodo da habitação, além do que se apresenta na proposta. Nota-se que a proposta dada não se atenta aos usos, mas a uma função pré-determinada para cada cômodo. Entendendo o conceito de função como resposta da pergunta "qual o papel?", subentende-se que está estritamente ligado a uma especificidade, sendo o que caracteriza algo. Seria como afirmar, por exemplo, que o dormitório é o cômodo destinado para dormir. No entanto, o conceito de uso é mais abrangente, pois engloba as várias funções, seja de um espaço físico, habitação ou mobiliário. Logo, quando se questiona "para o que serve?", subentende-se as várias possibilidades de utilizar algo.

Por meio do leiaute proposto, percebe-se maior preocupação em atender questões de função do que realmente de usos. Afinal, um dormitório pode ser usado para dormir, relaxar, conviver, estudar, trabalhar ou até mesmo se alimentar. Tudo varia de acordo com os hábitos e costumes dos usuários. As habitações estudadas podem então apresentar dificuldades de uso considerando o número de pessoas a que se propõe atender, pois restringe as sobreposições positivas e favorece sobreposições negativas, como, por exemplo, secar roupas em varal, no dormitório, assim como restringe usos que estão ligados a fatores culturais ou de hábitos, como, por exemplo, não possibilitar que a cozinha possa se relacionar diretamente, ou comportar usos direcionados à convivência (Apartamento 2), ou até mesmo de inviabilizar a opção estocagem/armazenagem em áreas como a de serviço e banheiros (Apartamento 1). 
Outra constatação é a ineficiência do espaço em comportar o arranjo, composto de mobiliário e equipamentos, referindo-se nesse momento apenas às dimensões físicas. Ao considerar as dimensões de uso, os pontos críticos se agravam, evidenciando que o espaço físico da habitação e de seus compartimentos, quando não comportam as dimensões de uso, as inviabilizam ou dificultam com o congestionamento de várias dimensões de uso. Ou seja, as dimensões de uso não são comportadas pelo espaço, quando se percebe que extrapolam as barreiras físicas, construtivas dos apartamentos. A inviabilização dessas dimensões ocorre devido a sua sobreposição negativa, não restando espaço nem mesmo para circulação de pessoas. Já o congestionamento ocorre quando vários móveis têm suas dimensões de uso sobrepostas. Em alguns casos, essa sobreposição é inevitável, mas não são prejudiciais, ou seja, não inviabilizam o uso de outro equipamento ou móvel.

Figura 6 - Nível de dificuldade dos moradores em relação ao desenvolvimento de atividades na unidade habitacional - Apartamento 1

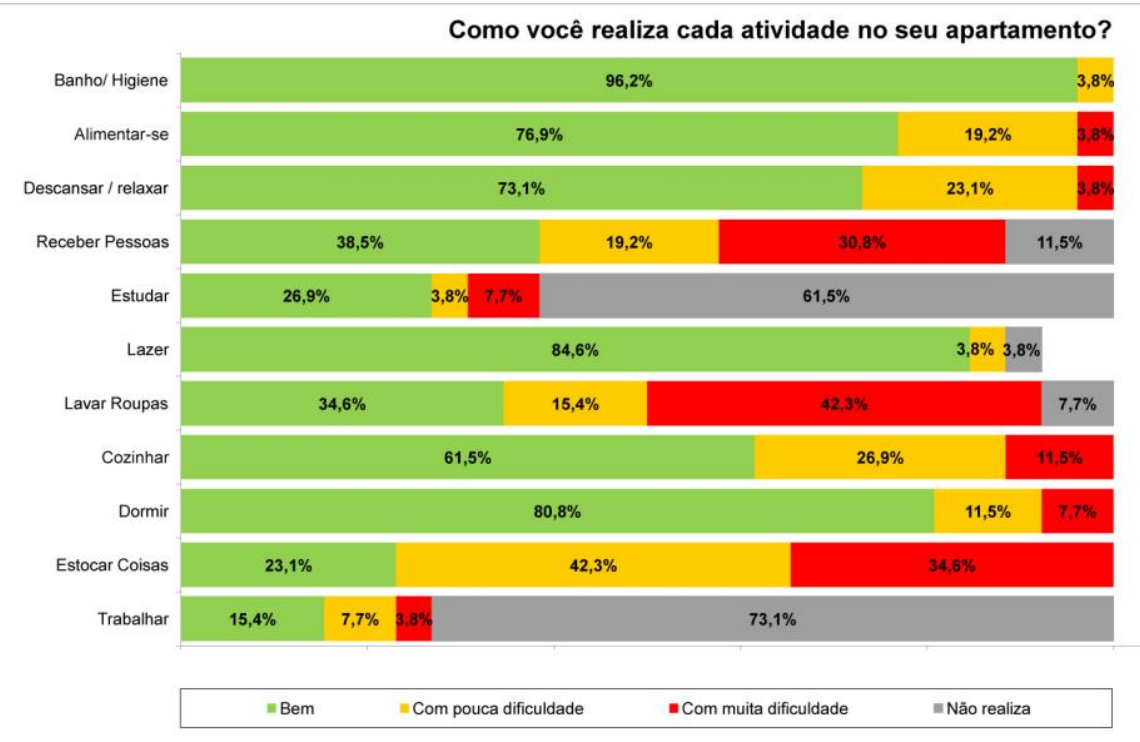

Figura 7 - Nível de dificuldade dos moradores em relação ao desenvolvimento de atividades na unidade habitacional - Apartamento 2

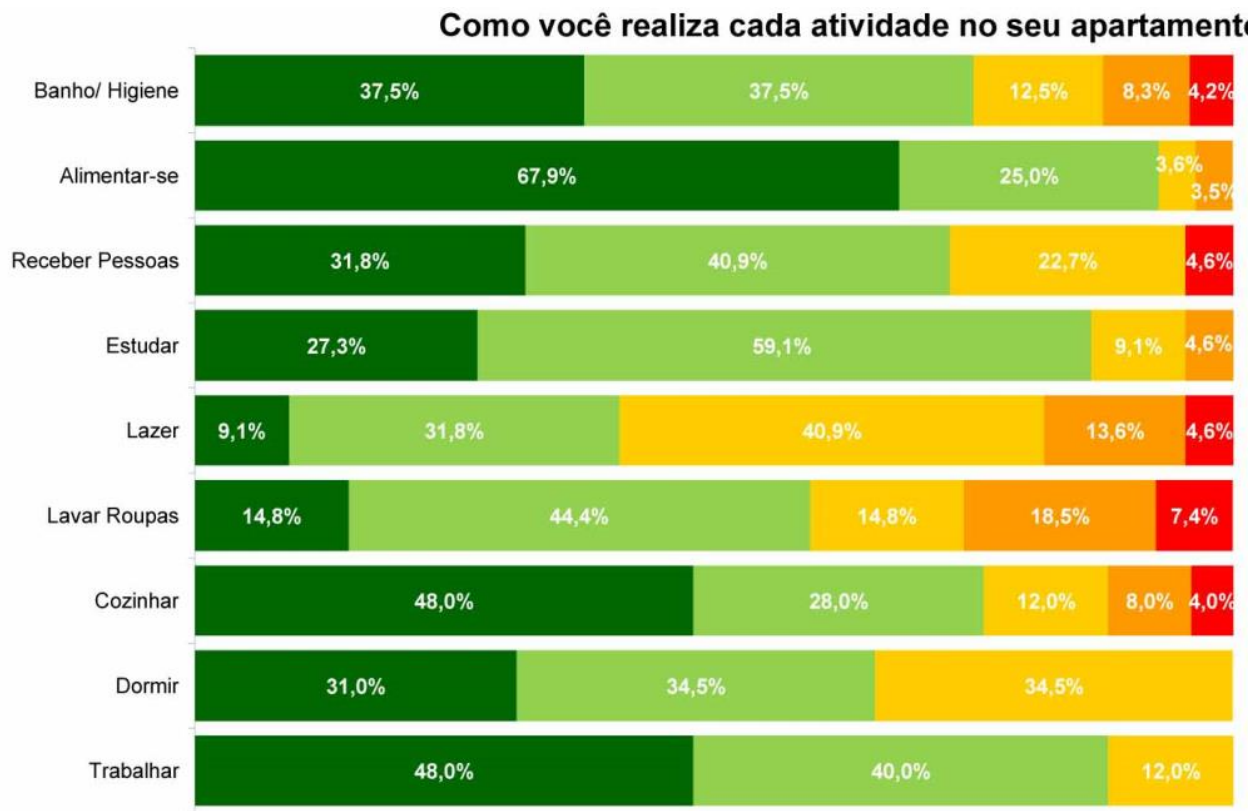

Fonte: gráficos da Avaliação Pós-ocupação fornecido pelo grupo de pesquisa da pesquisa "Habitar vertical” (2013). 
Figura 8 - Análise de usos da habitação

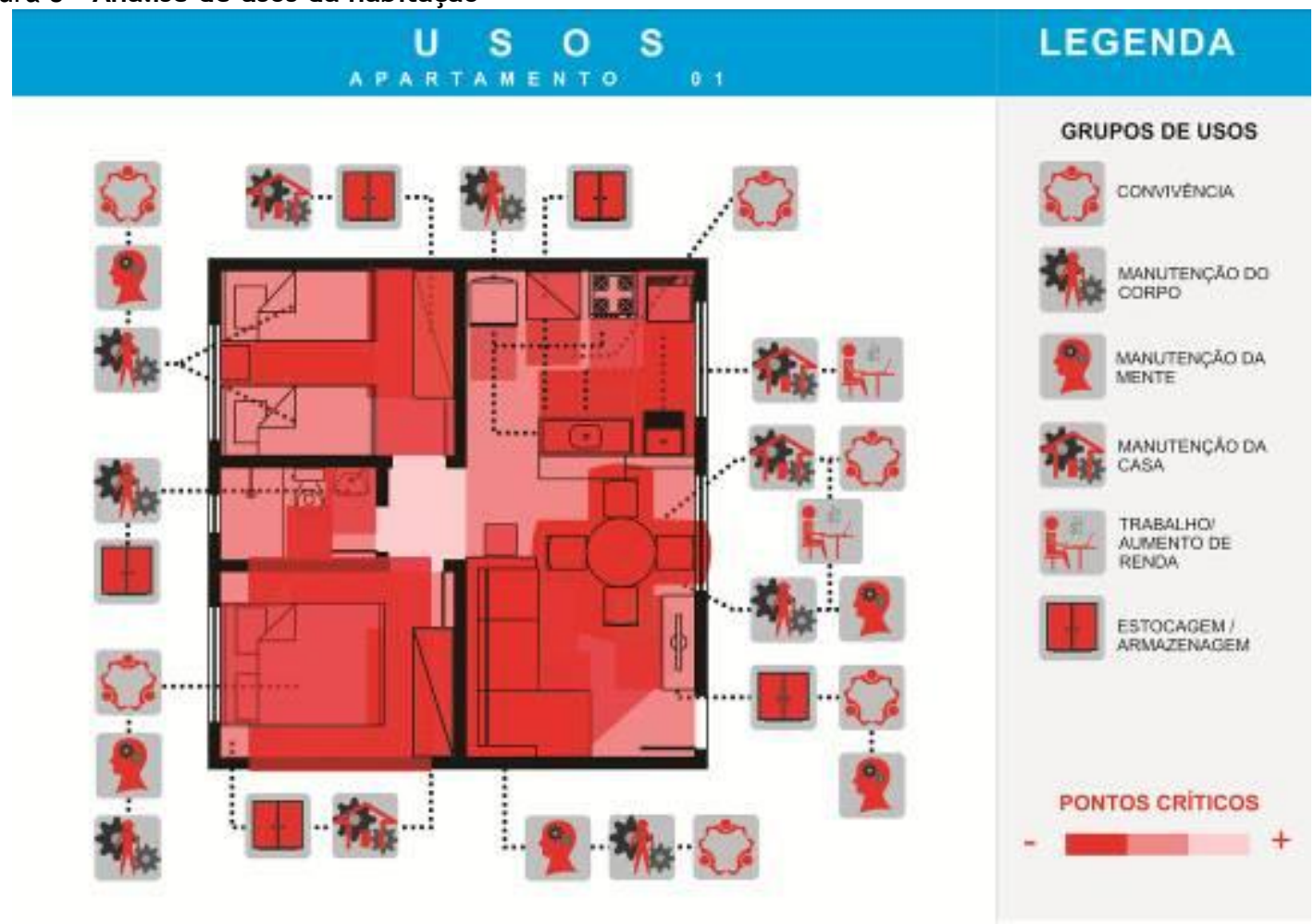

Figura 9 - Análises de usos da habitação

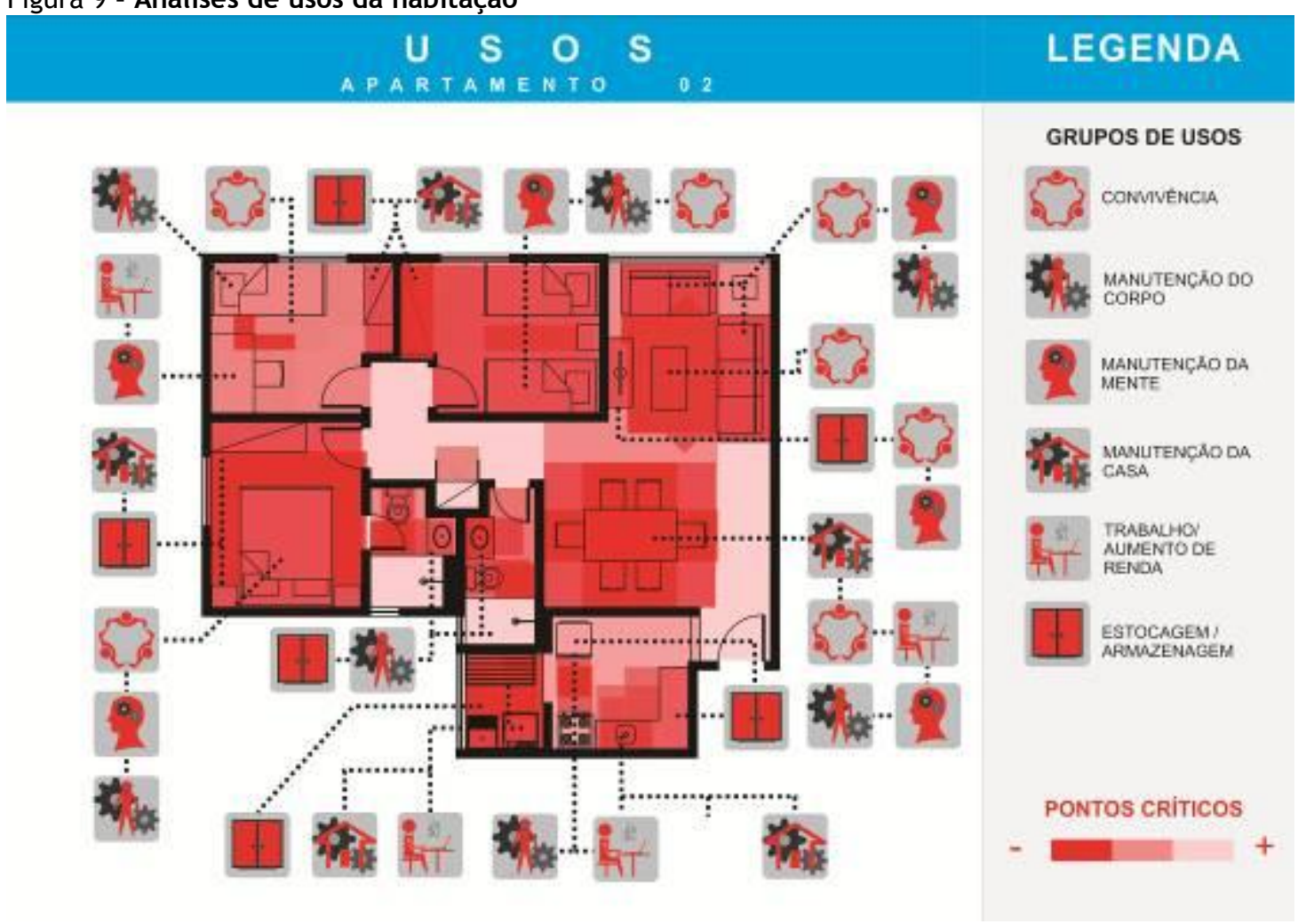


O Apartamento 1 dá indícios de maiores problemas com relação aos usos, especialmente nas áreas dos dormitórios, sala e área de serviço/lavanderia. O Apartamento 2 apresenta pontos menos críticos na área da sala, por exemplo, por se tratar de um espaço com dimensões maiores. Contudo, percebe-se que a configuração formal desse espaço pode ser um dos motivos da acentuação de problemas com relação às dimensões de uso dos móveis e equipamentos. As áreas destinadas apenas à circulação podem ser entendidas como pontos ociosos que poderiam ser mais bem aproveitados, caso o espaço permitisse maior flexibilidade na sua organização e distribuição formal.

Visto isso, recomenda-se que para atender ao conceito de uso, no intuito de qualificar a habitação, os espaços sejam dotados de multifuncionalidade ou não hierarquizados, integrados, sem função predeterminada, podendo ser organizados a partir de móveis escamoteáveis, retráteis, leves ou deslizantes, cuja distinção do cômodo se dá pela ocorrência da ação praticada. Também são recomendáveis móveis multifuncionais como parte de subsistema (modular), ou independente, como, por exemplo, mesas com dimensões reguláveis (extensível, altura regulável), assim como móveis dotados de adaptabilidade, para que o usuário tenha condições de empregar diferentes ações. Acredita-se que a adaptabilidade pode ser alcançada a partir de estudos de design frente à forma e tecnologia de materiais.

\section{Considerações finais}

Compreende-se que projetar e produzir a habitação requer interdisciplinaridade e igualdade de papéis. Do arquiteto ao designer, da indústria da construção à indústria moveleira, do marketing e publicidade ao usuário, todos devem ser conscientes de seus direitos e deveres de intervenção sobre a moradia. Pensar os espaços, com vistas apenas à economia e ao lucro, confere evidências de que o ciclo e o sistema de produção imobiliária são insustentáveis. Assim, a inovação da pesquisa está no fato de que é preciso reconhecer a volatilidade dos modos de morar, que, embora frequentemente discutido em estudos de arquitetura, ainda se encontra defasado em pesquisas específicas de design de interiores, que muito colaborariam com a reafirmação da área como elementar para a configuração do ambiente, ultrapassando o sentido meramente estético.
Portanto, este trabalho afirma a importância da consideração sobre as noções de uso, como conceito-chave, das quais partem e se relacionam outros conceitos que agem como colaboradores na qualificação das habitações, como os conceitos de flexibilidade, adequação, apropriação, privacidade e ergonomia. Afinal, o ato de morar é elementar à vida humana, e são essas noções tratadas como conceitos qualificadores que constituem a habitação, dotando-a de eficiências práticas e representações simbólicas. Sendo assim, acreditase que não só a habitação mas também seu conjunto de equipamentos e mobiliário devem ser pensados e construídos sob a orientação destes parâmetros, igualmente.

\section{Referências}

ABREU, R. Estratégias de flexibilidade na habitação coletiva: o caso holandês. Lisboa, 2005. 239 f. Dissertação Mestrado em Construção, Instituto Superior Técnico. Universidade Técnica de Lisboa, Lisboa, 2005.

ABREU, R.; HEITOR, T. Estratégias de Flexibilidade na Arquitectura Doméstica Holandesa: da conversão à multifuncionalidade. Portal Infohabitar - Revista Eletrônica do Grupo Habitar, Lisboa, jan. 2007. Disponível em: <http://infohabitar.blogspot.com.br/2007/01/estrat gias-de-flexibilidade-na.html >. Acesso em: 05 de setembro de 2013.

BARROS, R. R. M.; PINA, S. A. M. G. Sinfonia Inacabada da Habitação Coletiva: lições a partir do PREVI para uma arquitetura de possibilidades. Ambiente Construído, Porto Alegre, v. 12, n. 3, p. 7-26, jul./set. 2012.

\section{BENEVOLO, L. História da Arquitetura}

Moderna. 3. ed. São Paulo: Perspectiva, 1998.

BONSIEPE, G. A Tecnologia da Tecnologia. São Paulo: Editora Edgard Blucher, 1983.

BERNARD, Y. Contribuição da Psicologia Ambiental Para Políticas de Construção de Moradias. Psicologia USP, São Paulo, v. 16, n. 12, p. 213-222, 2005.

BOUERI, J.; PEDRO, J.B.; SCOARIS, R. O. Análise das Exigências de Áreas Aplicávies às Habitações do Programa "Minha Casa Minha Vida". Cadernos Edifícios: qualidade espacial e funcional da habitação, Lisboa, p. 89-106, 2012.

BOUERI, J. Antropometria: fator de dimensionamento da habitação. São Paulo, 1989. 368 f. Tese (Doutorado em Engenharia Civil) Faculdade de Arquitetura e Urbanismo, Universidade de São Paulo, São Paulo, 1989. 
BOUERI, J. J. Antropometria Aplicada à Arquitetura, Urbanismo e Desenho Industrial. São Paulo: Estação das letras e Cores Editora, 2008.

BOUERI, J. J. Roteiro: dimensionamento da habitação. São Paulo: FAU-USP, 2014. Notas de aulas. Disponível em: <https://www.academia.edu/7226515/2014_Roteir o_Dimensionamento_da_Habita\%C3\%A7\%C3\% A3o>. Acesso em: 11 fev. 2015.

BRANDÃO, D. Q. Diversidade e Potencial de Flexibilidade de Arranjos Espaciais de Apartamentos: uma análise do produto imobiliário brasileiro. Florianópolis, 2002. $443 \mathrm{f}$. Tese (Doutorado em Engenharia de Produção) Escola de Engenharia, Universidade Federal de Santa Catarina, Florianópolis, 2002.

BRANDÃO, D. Q. Tipificação e Aspectos Morfológicos de Arranjos Espaciais de Apartamentos no Âmbito da Análise do Produto Imobiliário Brasileiro. Ambiente Construído, Porto Alegre, v. 3, n. 1, p. 35-53, jan./mar. 2003.

BRANDÃO, D. Q. Avaliação da Qualidade de Arranjos Espaciais de Apartamentos Baseada em Aspectos Morfo-Topológicos e Variáveis Geométricas que Influenciam na Racionalização Construtiva. Ambiente Construído, Porto Alegre, v. 6, n. 3, p. 53-67, jul./set. 2006.

CARDOSO, R. Uma Introdução à História do Design. 3. ed. São Paulo: Edgard Blücher, 2008.

CARVAlHO, J. P. A Tipologia dos Edifícios de Apartamentos e Sua Relação Com o Tecido Urbano da Cidade: um estudo de suas transformações nos últimos 40 anos. São Paulo, 2008. 224 f. Dissertação (Mestrado em Planejamento Urbano e Regional) - Faculdade de Arquitetura e Urbanismo, Universidade de São Paulo, São Paulo, 2008.

DEVIDES, M. T. C. Design, Projeto e Produto: O desenvolvimento de móveis nas indústrias do Pólo Moveleiro de Arapongas, PR. Bauru, 2006. 120 f. Dissertação (Mestrado em Desenho Industrial) - Faculdade de Arquitetura, Artes e Comunicação, Universidade Estadual Paulista “Júlio de Mesquita Filho", Bauru, 2006.

FINKELSTEIN, C. W. Flexibilidade na Arquitetura Residencial: um estudo sobre o conceito e sua aplicação. Porto Alegre, 2009. Dissertação (Mestrado em Arquitetura) Faculdade de Arquitetura e Urbanismo, Universidade Federal do Rio Grande do Sul, Porto Alegre, 2009.
FOLZ, R. R. Industrialização da Habitação Mínima: discussão das primeiras experiências de arquitetos modernos - 1920-1930. Cadernos de Arquitetura e Urbanismo, Belo Horizonte, v. 12, n. 13, p. 95-112, dez. 2005.

FOLZ, R. R. Mobiliário na Habitação Popular. São Carlos, 2002. 240 f. Dissertação (Mestrado em Arquitetura e Urbanismo) - Escola de Engenharia de São Carlos, Universidade de São Paulo, São Carlos, 2002.

FOLZ, R. R. Projeto Tecnológico Para Produção de Habitação Mínima e Seu Mobiliário. São Carlos, 2008. 373 f. Tese (Doutorado em Arquitetura e Urbanismo) - Escola de Engenharia de São Carlos, Universidade de São Paulo, São Carlos, 2008.

GREVEN, H. A.; BALDAUF, A. S.

F. Introdução à Coordenação Modular da Construção no Brasil: uma abordagem atualizada. Porto Alegre: ANTAC, 2007. (Coleção Habitare, 9).

HERTZBERGER, H. Lições de Arquitetura. São Paulo: Martins Fontes, 1996.

KENCHIAN, A. Estudo de Modelos e Técnicas Para Projeto e Dimensionamento dos Espaços da Habitação. São Paulo, 2005. 308 f. Dissertação (Mestrado em Arquitetura) - Faculdade de Arquitetura e Urbanismo, Universidade de São Paulo, São Paulo, 2005.

KENCHIAN, A. Qualidade Funcional no Programa e Projeto da Habitação. São Paulo, 2011. 543 f. Tese (Doutorado em Arquitetura) Faculdade de Arquitetura e Urbanismo, Universidade de São Paulo, São Paulo, 2011.

LÖBACH, B. Design Industrial: bases para a configuração dos produtos industriais. São Paulo: Blucher, 2001.

PANERO, J.; ZELNIK, M. Dimensionamento Humano Para Espaços Interiores: um livro de consulta e referência para projetos. São Paulo: Gilli, 2002.

PEDRO, J. B. et al. Dimensões do Mobiliário e do Equipamento na Habitação. Lisboa: Lenec, 2011.

PEDRO, J. B. Programa Habitacional: espaços e compartimentos. Lisboa: Lenec, 2014.

PEDRO, J. B. Programa Habitacional: habitação. Lisboa: Lenec, 2002.

PINHO, A. Conexão: apartamentos e mídias em Belo Horizonte. São Carlos, 2007. 147 f. Dissertação (Mestrado em Arquitetura e Urbanismo) - Escola de Engenharia de São Carlos, Universidade de São Paulo, São Carlos, 2005. 
REQUENA, C. A. J. Habitar Híbrido:

interatividade e experiência na era da cibercultura. São Carlos, 2007. 147 f. Dissertação (Mestrado em Arquitetura e Urbanismo) - Escola de Engenharia de São Carlos, Universidade de São Paulo, São Carlos, 2007.

RYBCZYNSKI, W. Casa: pequena história de uma ideia. Rio de Janeiro: Record, 1996.

SCHMIDT, R. et al. What Is the Meaning of Adaptability in the Building Industry?

Lughborough University. United Kingdom, 2010.

Disponível em: <http://adaptablefutures.com>.

Acessado em: 20 jan. 2015.

SCHNEIDER, T.; TILL, J. Flexible Housing: opportunities and limits. Architectural Research Quarterly, v. 9, n. 2. p. 157-166, 2005a.

SCHNEIDER, T.; TILL, J. Flexible housing: the means to the end. Architectural Research Quarterly, v. 9, n. 3/4, p. 287-296, 2005b.

TRAMONTANO, M. Habitações, Metrópoles e Modos de Vida: por uma reflexão sobre o espaço doméstico contemporâneo. In: PRÊMIO Jovens Arquitetos, categoria "Ensaio Crítico", 3., São Paulo: Instituto dos Arquitetos do Brasil / Museu da Casa Brasileira, 1997. Disponível em: <http://www.nomads.usp.br/site/livraria/livraria.htl >. Acesso em: 17 dez. 2014.
TRAMONTANO, M. Apartamentos, Arquitetura e Mercado: estado das coisas. In: OFICINA Verticalização das cidades brasileiras. São Paulo, 2006. Disponível em:

<http://www.nomads.usp.br/site/livraria/livraria.ht $\mathrm{ml}>$. Acesso em: 03 jan. 2014.

VILLA, S. B. Apartamento Metropolitano: habitações e modos de vida na cidade de São Paulo. São Carlos, 2002. 222 f. Dissertação (Mestrado em Arquitetura e Urbanismo) - Escola de Engenharia de São Carlos, Universidade de São Paulo, São Carlos, 2002.

VILLA, S. B. Morar em Apartamentos: a produção dos espaços privados e semi-privados nos edifícios ofertados pelo mercado mobiliário no século XXI em São Paulo e seus impactos na cidade de Ribeirão Preto. Critérios para avaliação pós-ocupação. São Paulo, 2008. 358 f. Tese (Doutorado em Arquitetura e Urbanismo) Faculdade de Arquitetura e Urbanismo, Universidade de São Paulo, São Paulo, 2008.

VILLA, S. B.; ORNSTEIN, S. W. (Orgs.). Qualidade Ambiental na Habitação: avaliação pós-ocupação. São Paulo: Oficina de Textos, 2013.

\section{Agradecimentos}

À Fundação de Amparo à Pesquisa do Estado de Minas Gerais (Fapemig) pela bolsa concedida, para efetuação da pesquisa de mestrado na qual se insere este artigo, bem como ao CNPq e PROPP UFU, pelo apoio no desenvolvimento da pesquisa.

Rafaela Nunes Mendonça

Faculdade de Arquitetura, Urbanismo e Design | Universidade Federal de Uberlândia | Av. João Naves Ávila, 2121, Santa Mônica | Uberlândia - MG - Brasil | CEP 38400-902 | Tel.: (34) 3239-4435 | E-mail: rafaelanunes.r@gmail.com

Simone Barbosa Villa

Faculdade de Arquitetura e Design | Universidade Federal de Uberlândia | Tel.: (34) 3239-4373 | E-mail: simonevilla@yahoo.com

Revista Ambiente Construído

Associação Nacional de Tecnologia do Ambiente Construído

Av. Osvaldo Aranha, $99-3^{\circ}$ andar, Centro

Porto Alegre - RS - Brasil

CEP $90035-190$

Telefone: +55 (51) 3308-4084

Fax: +55 (51) 3308-4054

www.seer.ufrgs.br/ambienteconstruido

E-mail: ambienteconstruido@ufrgs.br

270 Mendonça, R. N.; Villa, S. B. 